\title{
Electrostatics cause the molecular chaperone BiP to preferentially bind oligomerized states of a client protein
}

\author{
Judy L.M. Kotler, Wei-Shao Wei, Erin E. Deans, Timothy O. Street
}

Department of Biochemistry, Brandeis University, Waltham, Massachusetts 02454

\begin{abstract}
Hsp70-family chaperones bind short monomeric peptides with a weak characteristic affinity in the low micromolar range, but can also bind some aggregates, fibrils, and amyloids, with low nanomolar affinity. While this differential affinity enables Hsp70 to preferentially target potentially toxic aggregates, it is unknown how Hsp70s differentiate between monomeric and oligomeric states of a target protein. Here we examine the interaction of $\mathrm{BiP}$ (the Hsp70 paralog in the endoplasmic reticulum) with prolGF2, the pro-protein form of IGF2 that includes a long and mostly disordered E-peptide region that promotes prolGF2 oligomerization. We discover that electrostatic attraction enables the negatively charged BiP to bind positively charged E-peptide oligomers with low nanomolar affinity. We identify the specific BiP binding sites on prolGF2, and although some are positively charged, as monomers they bind BiP with characteristically low affinity in the micromolar range. We conclude that electrostatics enable BiP to preferentially recognize oligomeric states of prolGF2. Electrostatic targeting of Hsp70 to aggregates may be broadly applicable, as all the currently-documented cases in which $\mathrm{Hsp70}$ binds aggregates with high-affinity involve clients that are expected to be positively charged.
\end{abstract}

\section{Introduction}

Hsp70-family chaperones are crucial molecular machines involved in folding nascent polypeptides, holding non-native state protein folding intermediates, and disaggregating misfolded proteins $\mathrm{s}^{1,2}$. They bind exposed, extended, and hydrophobic segments of unfolded, misfolded, or partially-folded proteins ${ }^{3,4}$. Hsp70s are composed of two domains held together by an interdomain linker: a nucleotidebinding domain (NBD) and substrate-binding domain (SBD) (Figure 1A). The SBD contains a beta-sheet region $\left(\mathrm{SBD}_{\beta}\right)$, including the hydrophobic substrate-binding cleft, and an alpha helical lid $\left(\mathrm{SBD}_{\alpha}\right)$. Hsp70s populate two major conformations that are dictated by the nucleotide bound in the NBD. In the ATPbound conformation, the NBD and $\mathrm{SBD}_{\beta}$ are docked, the linker is bound to the NBD, and the $\mathrm{SBD}_{\alpha}$ lid is open to expose the $\mathrm{SBD}_{\beta}$ substrate-binding cleft ${ }^{5}$. After ATP is hydrolyzed, the NBD and $\mathrm{SBD}_{\beta}$ undock, and the $\mathrm{SBD}_{\alpha}$ lid closes onto the $\mathrm{SBD}_{\beta}$ substrate-binding cleft ${ }^{6}$. The ADP-bound conformation typically favors client binding, in which a client can be trapped between the $\mathrm{SBD}_{\beta}$ substrate-binding cleft and $\mathrm{SBD}_{\alpha}$ lid $^{5}$. BiP, like other Hsp70s, is negatively charged, much of which is contributed by the SBD (Figure $1 \mathrm{~A})$.

A range of neurodegenerative diseases are associated with the formation of protein aggregates and fibrils, and it is important to understand how Hsp70-type chaperones differentiate whether the "client" protein is in an oligomeric or monomeric state. In some cases Hsp70s bind clients with much higher affinity when the client is oligomeric. For example, human $\mathrm{Hsp} 70$ binds tau fibrils with low nanomolar affinity and tau monomers with micromolar affinity ${ }^{7}$. In contrast, human $\mathrm{Hsp} 70$ binds $\alpha$-synuclein fibrils and monomers with comparable low micromolar affinities ${ }^{8}$. It is unknown how Hsp70 achieves high 
affinity for oligomeric client states, and why this affinity enhancement is observed for some but not all oligomeric clients.

ProlGF2 is the pro-protein of insulin-like growth factor (IGF) 2, which is a member of the insulin family of hormones, and is a mitogen for fetal and placental cell growth ${ }^{9}$. ProlGF2 is targeted to the ER via an Nterminal (24 residue) ER-signaling sequence that is cleaved upon entrance to the ER. Following the signal sequence is the 67 residue mature hormone region and 89 residue positively-charged E-peptide (Figure 1B). Folded, $\alpha$-helical mature IGF2 contains three disulfide bonds, whereas the E-peptide is predicted to be mostly disordered and has minimal secondary structure ${ }^{10}$. Once folded, prolGF2 is translocated from the ER to the Golgi for further processing ${ }^{11}$. ProlGF2 is modified by Nacetylgalactosamine likely in the cis-Golgi, and sialic acid addition and oligosaccharide maturation in the trans-Golgi ${ }^{11}$. Modified prolGF2 is proteolytically cleaved twice by the proprotein convertase PC4: first to the intermediate form (residues 25-126) and then to mature IGF2 (25-91) (Figure 1B) ${ }^{12,13}$. The second cleavage liberates the hormone preptin $(93-126)^{14}$. Preptin, which has minimal structure ${ }^{15}$, is cosecreted with insulin and amylin and increases glucose-mediated insulin secretion from pancreatic $\beta$-cells ${ }^{16}$. An intermediate cleavage product (25-111) has also been observed in bovine serum ${ }^{17}$. The positivelycharged cleavage motifs confer a net charge of +9 to the E-peptide, while mature IGF2 has a net charge of -1 .

57 Previous work demonstrated that proIGF2 forms dynamic oligomers, where the E-peptide region is 58 necessary for oligomerization ${ }^{10}$. BiP and the ER Hsp90 paralog Grp94 regulate the assembly of these oligomers while exerting only a minimal influence on the folding of prolGF $2^{10}$. It was left unknown where and how BiP and Grp94 interact with prolGF2. For example, whether BiP and Grp94 compete for binding sites on prolGF2 or whether they recognize different areas, and how tightly these chaperones interact with prolGF2 oligomers. Here, by dissecting the mechanism by which BiP recognizes prolGF2 oligomers, we discover that electrostatics play a defining role. Given the available data in the literature, electrostatics provide a plausible explanation of why Hsp70 chaperones preferentially bind some aggregated clients, such as tau, but not other clients such as $\alpha$-synuclein. 

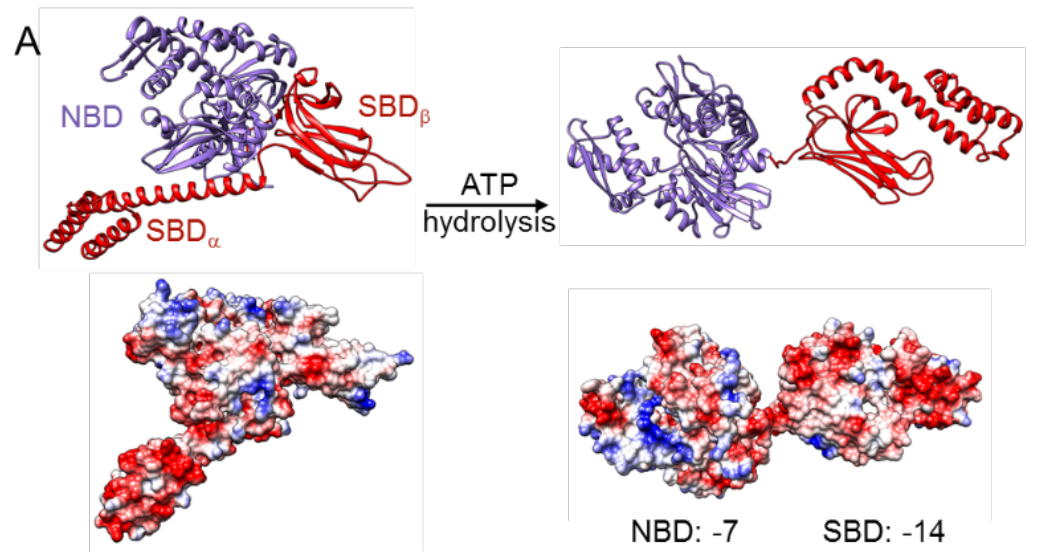

B ProlGF2 Golgi endoprotease processing:

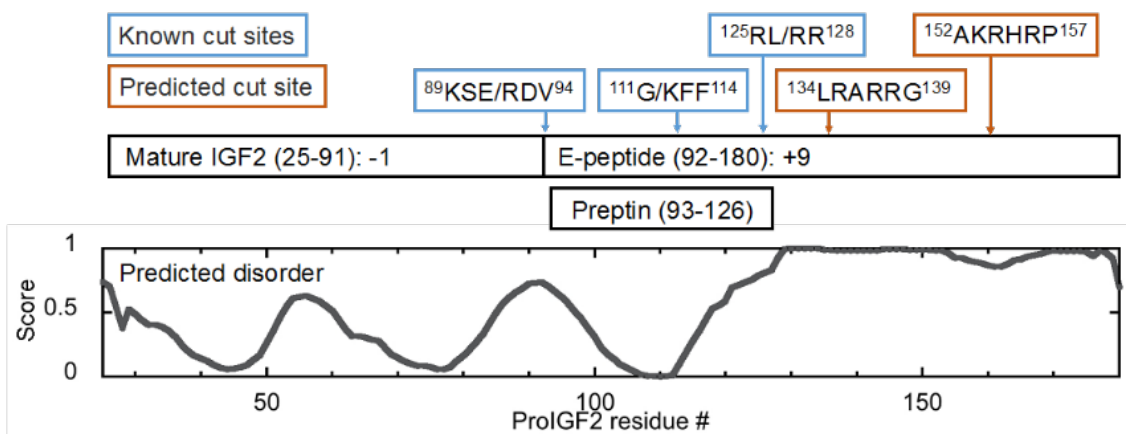

Figure 1. Overview of BiP and prolGF2. (A) BiP's two major conformations are shown in ribbon and surface, with calculated electrostatic potential coloring (red for negative charge and blue for positive charge) ${ }^{18}$. BiP's ATP-bound conformation has NBD and SBD docked (PDB:5E84), while BiP's ADP-bound conformation has domains undocked (BiP homology model, PDB:2KHO) ${ }^{5,6}$. The net charges of the NBD and SBD are noted below the ADP conformation. (B) Known and predicted endoprotease processing sites on prolGF2. "/" indicates known cut site within sequence. Predicted sites are based on furin protease motif, "xBxBB/ $\mathrm{x}$ ", where $x$ is an uncharged and B is a basic (Arg or Lys) amino acid". Amino acid sequences shown in boxes are from Mus musculus prolGF2. Disorder for prolGF2 amino acid sequence was predicted by PONDR ${ }^{20}$.

\section{Results}

\section{BiP binds E-peptide oligomers with high affinity}

We first utilized dynamic light scattering (DLS) to quantify the size of prolGF2 and E-peptide oligomers and the range of conditions in which oligomers are formed. ProlGF2 oligomers are larger than E-peptide oligomers and in both cases their size increases with protein concentration (Supplemental Figure 1A). In these experiments prolGF2 was maintained in a reduced and non-native state by the reducing agent TCEP. We evaluated proIGF2 concentrations at $1 \mu \mathrm{M}$ and below, because at higher concentrations prolGF2 forms large particles that produce optical light scattering (Supplemental Figure 1B), which prevents accurate size determination by DLS. E-peptide oligomers and mature IGF2 do not scatter light at concentrations up to $5 \mu \mathrm{M}$ (Supplemental Figure 1B). For prolGF2, the build-up of light-scattering 
particles is slower at $\mathrm{pH} 6$ versus at $\mathrm{pH} 7.5$ (Supplemental Figures 1C,D), so the first experiments were performed at this lower $\mathrm{pH}$ condition.

Because the hydrodynamic radius $\left(R_{H}\right)$ of prolGF2 and E-peptide oligomers are in the range of hundreds of nanometers (Supplemental Figure $1 \mathrm{~A}$ ), much larger than $\mathrm{BiP}\left(\mathrm{R}_{\mathrm{H}} \sim 3 \mathrm{~nm}^{10}\right)$, we reasoned that the

92 binding of BiP to these oligomers could be measured by fluorescence depolarization (FP). Specifically, if BiP preferentially binds monomers or small oligomers then a negligible increase in polarization is expected, due to the small size of prolGF2 (17 kDa) relative to BiP $(70 \mathrm{kDa})$, whereas if BiP preferentially binds large oligomers then a large change in polarization is anticipated (Figure $2 \mathrm{~A}$ ). Figure $2 \mathrm{~B}$ shows that BiP binds both prolGF2 and E-peptide oligomers, whereas no FP change is observed for mature IGF2. BiP binding to proIGF2 and E-peptide oligomers is observed under both ATP (Figure 2B) and ADP (Supplemental Figure 2) conditions. The larger amplitude of FP change for prolGF2 versus E-peptide is consistent with the larger size of prolGF2 oligomers. In both cases the FP signal increases with protein concentration similar to the increasing size of E-peptide and prolGF2 oligomers as measured by DLS.

101 BiP's SBD is responsible for the high-affinity binding of prolGF2 oligomers because the isolated BiP NBD has only weak interactions with prolGF2 (Supplemental Figure 2). 
A

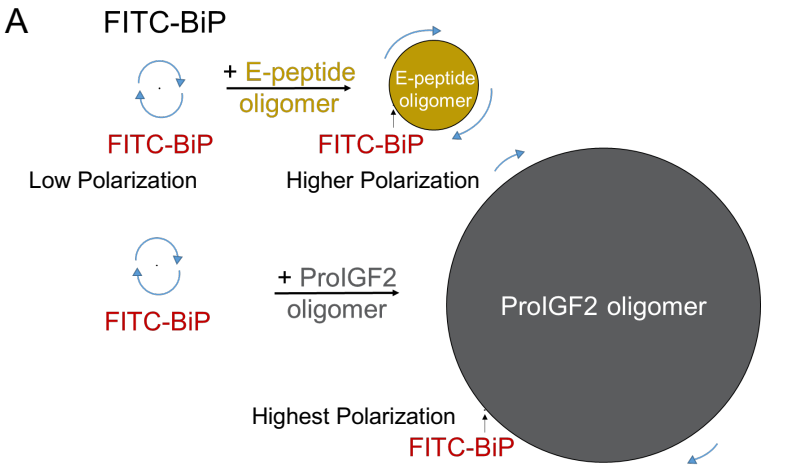

C $\quad$ BiP $_{\mathrm{SBD}}$ FRET
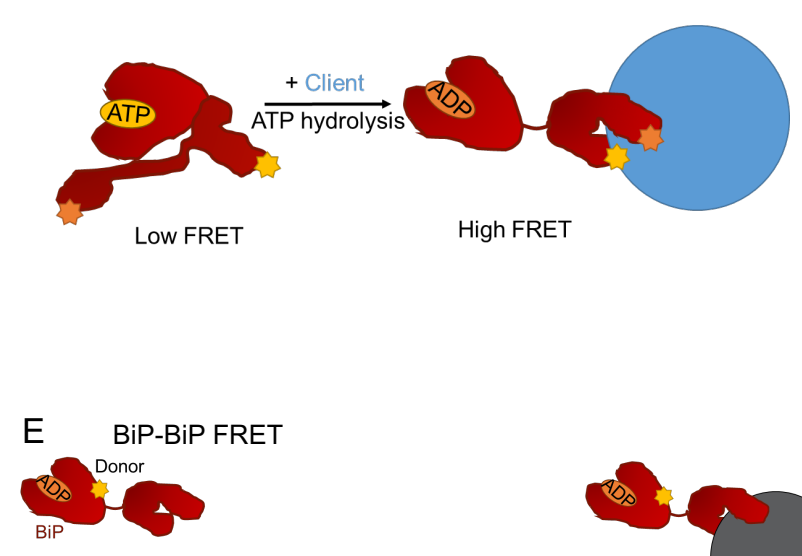

103 peptide. Error bars are the SEM for three replicates.
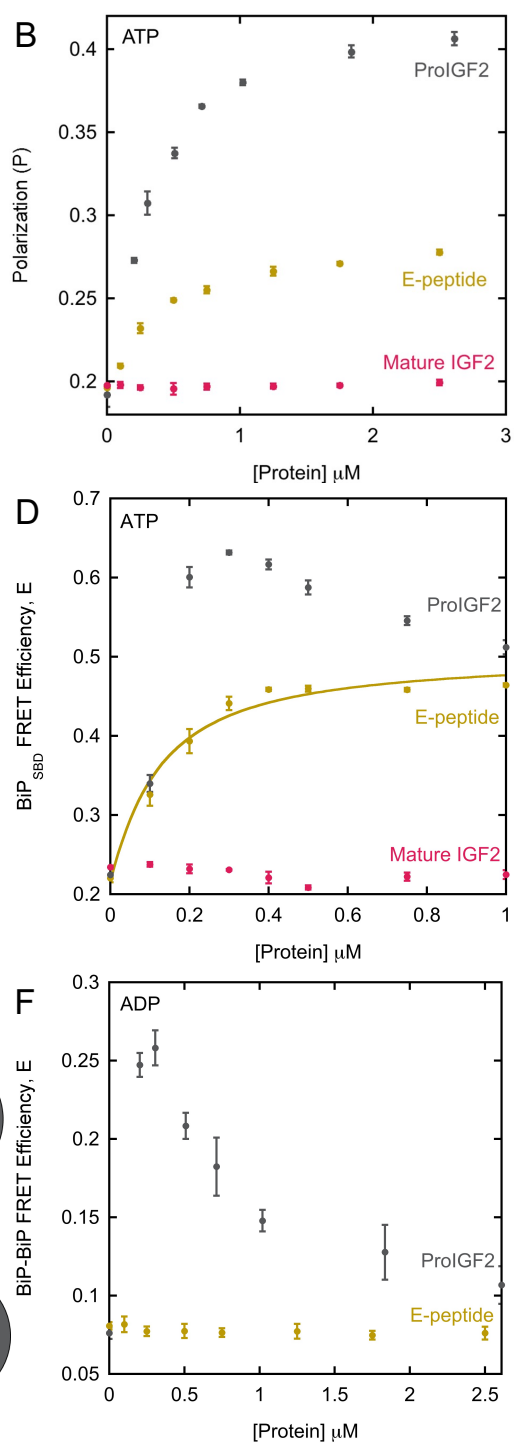

Figure 2. BiP binds prolGF2 and E-peptide oligomers. (B) Schematic of FITC-BiP fluorescence depolarization assay. BiP, E-peptide oligomer, and prolGF2 oligomer relative sizes are shown at $1 \mu \mathrm{M}$. Blue arrows indicate relative tumbling rates where longer arrows indicate faster tumbling and shorter arrows indicate slower tumbling. (C) FP assay with FITC-BiP and proIGF2, E-peptide, and mature IGF2 in

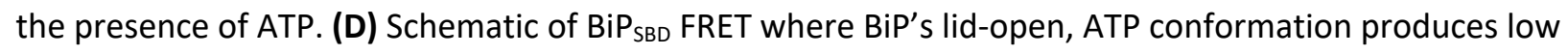
FRET efficiency (E) and BiP's lid-closed and client-bound, ADP-conformation produces high FRET efficiency. Donor and acceptor labels can be present in both locations on the SBD due to labeling protocol, but only one of each is shown for clarity. BiP and oligomer sizes are not to scale. (E) BiPSBD FRET data for proIGF2, E-peptide and mature IGF2. Solid line is a fit to equation 4, with $K_{D}=0.098 \pm$ $0.010 \mu \mathrm{M}$. (F) Schematic of BiP-BiP FRET experiment with BiP separately-labeled with either donor or acceptor fluorophore. BiP and oligomer sizes are not to scale. (G) BiP-BiP FRET data for prolGF2 and E-

The above FP assay cannot yield a binding affinity because the FP signal is determined by the oligomer size, however, given that large FP changes are observed at sub-micromolar concentrations of prolGF2 
and E-peptide, the FP data suggests sub-micromolar affinity. To determine BiP affinity for oligomers, we utilized a FRET assay measuring the conformation of BiP's SBD ${ }^{21,22}$. This BiPSBD FRET assay produces low FRET efficiency in the ATP-bound, lid-open state and high FRET efficiency in the ADP-bound and lidclosed state (Figure 2C). ProlGF2, E-peptide, and mature IGF2 were assayed with BiPSBD FRET in the presence of ATP (Figure 2D). BiPSBD FRET increases upon binding prolGF2 and the E-peptide oligomers, indicating lid closure, as is typically observed when an $\mathrm{Hsp70}$ binds a peptide client ${ }^{21,23}$. No lid-closure is observed in the presence of mature IGF2. The FRET change for E-peptide can be fit with a binding curve (Figure 2D, solid line) yielding a binding affinity of approximately $100 \mathrm{nM}$, approximately 100 -fold higher affinity than is typical for BiP binding a monomeric peptide under ATP conditions. While measuring BiP's conformation is an indirect determination of binding affinity, later we demonstrate that this indirect method agrees with BiP affinities measured directly for peptides using an FP assay.

The lid closure of BiP in the presence of E-peptide oligomers could result from stable binding while the BiP ATPase cycle is stalled in the ADP state, or from BiP cycling through rounds of ATP binding and hydrolysis with accelerated ATPase kinetics that shift the conformational equilibrium towards the lid closed state. ATPase measurements support the latter case, as the BiP ATPase rate increases from 0.23 $\pm 0.01 \mathrm{~min}^{-1}$ to $1.53 \pm 0.02 \mathrm{~min}^{-1}$ in the presence of $2.5 \mu \mathrm{M}$ E-peptide. Due to the enhanced hydrolysis of ATP by BiP, the measured affinity under ATP conditions will have a contribution from the ADP-bound state, and we sought to measure this contribution. However, measuring BiP affinity under ADP conditions is challenging because BiP is maintained uniformly in the high-FRET lid-closed state, so no change in FRET efficiency is observed (Supplemental Figure 3). Therefore, we utilize ADP conditions with trace quantities of ATP, to enable a change of FRET to be measured. For example, commercial stocks of ADP contain 2\% ATP (see Figure 1 in Liu et al. ${ }^{24}$ ), which we remove by a pretreatment with hexokinase (HK, see Methods). In experiments with this residual ATP present (termed "ADP, no HK") or with an additional 5\% added ATP, we can measure BiP affinity to E-peptide oligomers under predominantly ADP conditions. In both cases, the measured BiP affinity to E-peptide oligomers is in the range of 10-20 nM (Supplemental Figure 3). The roughly ten-fold higher affinity of BiP for E-peptide oligomers under ADP versus ATP conditions is similar to the nucleotide dependence observed for other Hsp70s binding peptides ${ }^{25,26}$.

Unlike the $\mathrm{BiP}_{\mathrm{SBD}}$ FRET data with E-peptide oligomers in Figure 2D, which can be fit to a binding curve, for prolGF2 oligomers the FRET efficiency first rises above 0.5 and then falls back to a saturating value close to that observed for the E-peptide. Due to the fluorophore labeling scheme (Methods) the maximum FRET efficiency is 0.5 for a BiP monomer. However, if BiP monomers are positioned closely on an oligomer then FRET efficiencies above 0.5 could arise from an additional contribution from FRET between BiPs. We developed a FRET assay to detect when BiPs are in close proximity ("BiP-BiP FRET", Figure $2 \mathrm{E}$ ). Upon adding prolGF2, BiP-BiP FRET reaches a maximum at $0.3 \mu \mathrm{M}$ prolGF2, indicating multiple BiP's are occupying a single prolGF2 oligomer. Higher concentrations of prolGF2 decrease FRET (Figure 2F). At these higher concentrations of prolGF2 oligomers, with the same concentration of BiP, single BiPs will occupy different prolGF2 oligomers and FRET efficiency will decrease. Multiple BiPs binding per oligomer is not necessary for high affinity, however, because BiP-BiP FRET is not observed in experiments with E-peptide (Figure 2F).

Overall, we conclude that E-peptide oligomers are well-suited to uncover the origin of BiP's high affinity for oligomers. Unlike prolGF2, E-peptide oligomers are not confounded by BiP-BiP FRET, making the $\mathrm{BiP}_{S B D}$ FRET assay a powerful tool for measuring BiP affinity to oligomers. Furthermore, whereas prolGF2 
experiments are performed at low $\mathrm{pH}$ to limit the formation of very large oligomers that scatter light, Epeptide oligomers are well behaved at both low and high $\mathrm{pH}$ values (Supplemental Figure 1B) and BiP binds with comparable affinity at both pH 6.0 ( $\mathrm{K}_{\mathrm{D}}$ of $\left.98 \pm 10 \mathrm{nM}\right)$ and $\mathrm{pH} 7.5\left(\mathrm{~K}_{\mathrm{D}}\right.$ of $\left.130 \pm 10 \mathrm{nM}\right)$ under ATP conditions.

\section{Identification of BiP binding sites on prolGF2}

BiP binding sites can be predicted from primary sequence ${ }^{27}$ and three potential sites are on the Epeptide (Figure 3A, labeled 1, 2, and 3). Binding site 1 resides within the preptin region. We also evaluated BiP's interaction with the mature region of prolGF2. All E-peptide peptide constructs were labeled with FITC for FP measurements (Methods) and maintained at a low concentration (50 nM) in BiP binding experiments to suppress oligomerization. Indeed, in the absence of BiP sites 1-3 all have similar low polarization values of 0.07 (Supplemental Figures $4 A-C$ ) that are characteristic of monomeric peptides.

A

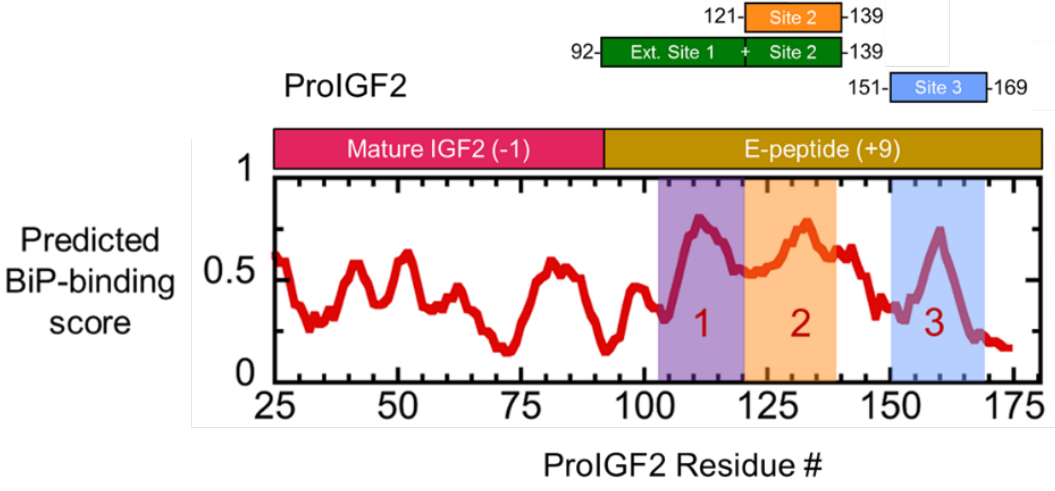

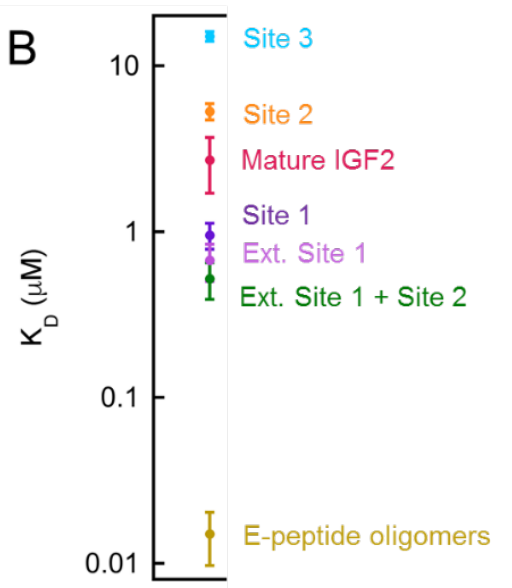

Figure 3. (A) BiP-binding sites (labeled 1,2 , and 3 ) as predicted by BiPPred ${ }^{27}$. Color shading indicates FITC-labeled peptide binding sites 1 (purple), 2 (orange), and 3 (blue). (B) Affinities of monomeric Epeptide fragments (from Supplemental Figure 4) and the oligomeric E-peptide (from Supplemental Figure 3). Measurements performed under ADP conditions. Error bars are the SEM for at least three binding curve replicates.

BiP binds all three binding-site peptides and mature IGF2 with low micromolar affinity, in the presence of ADP, and approximately 10-fold weaker affinity in the presence of ATP (Supplemental Figures 4A-D). Site 1 has the highest affinity for $\mathrm{BiP}\left(\mathrm{K}_{\mathrm{D}} \sim 1 \mu \mathrm{M}\right.$ under ADP conditions), a much weaker binding than is observed for E-peptide oligomers ( $\left.K_{D} \sim 10-20 \mathrm{nM}\right)$. While this difference in affinity could plausibly be explained if site 1 is not a complete BiP binding site, we confirmed that site 1 is complete by constructing E-peptide fragments centered at site 1 , that are extended in the $\mathrm{N}$-terminal direction (residues 92-120) and in the C-terminal direction (residues 92-139). Both "extended fragments" and site 1 bind BiP with similar affinity under ADP conditions (compare Supplemental Figures 4A, E, and F). Because the 92-139 fragment contains both site 1 and site 2, we can exclude the possibility that the high affinity of BiP to E-peptide oligomers is due to an avidity effect from these two closely spaced BiP binding sites. This is consistent with the absence of BiP-BiP FRET on the E-peptide (Figure 2F). Site 1 can 
outcompete site 2 in binding to BiP under ADP conditions, with characteristically slow displacement kinetics (Supplemental Figure 5A). We conclude that site 1 is the dominant BiP binding site on prolGF2.

Grp94 has minimal binding for sites 1-3 and mature IGF2 under both ATP and ADP conditions (Supplemental Figure 6), demonstrating that these sites are specific to BiP. Interestingly, site 1 binds non-specifically to BSA whereas sites $2 \& 3$ do not bind BSA (Supplemental Figure 7), suggesting that BiP's preferential binding to site 1 may serve a biological role in preventing non-specific interactions with this region of the E-peptide. We utilized the slow displacement kinetics of site 2 to test whether BiP binds Epeptide oligomers specifically. If BiP binds E-peptide oligomers specifically, a BiP:site 2 complex must first release site 2 before binding the E-peptide oligomer, and the displacement kinetics should be slow. If BiP binds E-peptide oligomers non-specifically no such displacement will be observed. E-peptide oligomers show slow displacement kinetics that are similar to that of site 1 and site 2 (Supplemental Figure 5B) indicating that BiP binds E-peptide oligomers specifically and in a manner similar to a typical peptide client, albeit with much higher affinity.

\section{Electrostatic steering enhances BiP affinity for E-peptide oligomers}

The charge difference between BiP and both prolGF2 and the E-peptide (Figure 1) suggests that high affinity binding might have an electrostatic contribution. If true, BiP affinity for prolGF2 and E-peptide oligomers should be salt dependent due to charge screening. The affinity of BiP for E-peptide oligomers as measured by $\mathrm{BiP}_{S B D}$ FRET is indeed highly salt dependent, where increasing the salt concentration weakens BiP's affinity for E-peptide oligomers under both ADP and ATP conditions (Figure 4A, Supplemental Figures $8 \mathrm{~A}-\mathrm{B}$ ). The highest salt concentration data in the presence of ATP requires fixing the saturating FRET efficiency value, and therefore these $K_{D}$ values are not as well defined and should be interpreted cautiously (these data are marked with an asterisk in Figure 4A). While salt-dependent affinities cannot be measured for BiP and prolGF2 because of BiP-BiP FRET (Figures 2D,F), the FP assay described in Figure 2A shows a loss of binding between BiP and prolGF2 oligomers with increasing salt (Supplemental Figure 8C).

The strong salt dependence of BiP binding E-peptide oligomers is observed with different salts ( $\mathrm{KCl}$, $\mathrm{NaCl}$, and $\mathrm{KI}$, see Table 1), as expected for electrostatic screening rather than a specific ionic interaction. ProlGF2 light scattering is minimally salt-dependent (Supplemental Figures $1 C, D$ ), and E-peptide does not scatter light at any salt condition tested (Supplemental Figure $1 \mathrm{C}$ ), suggesting that oligomer size changes cannot explain the strong salt-dependent biding of BiP to both prolGF2 and E-peptide. 

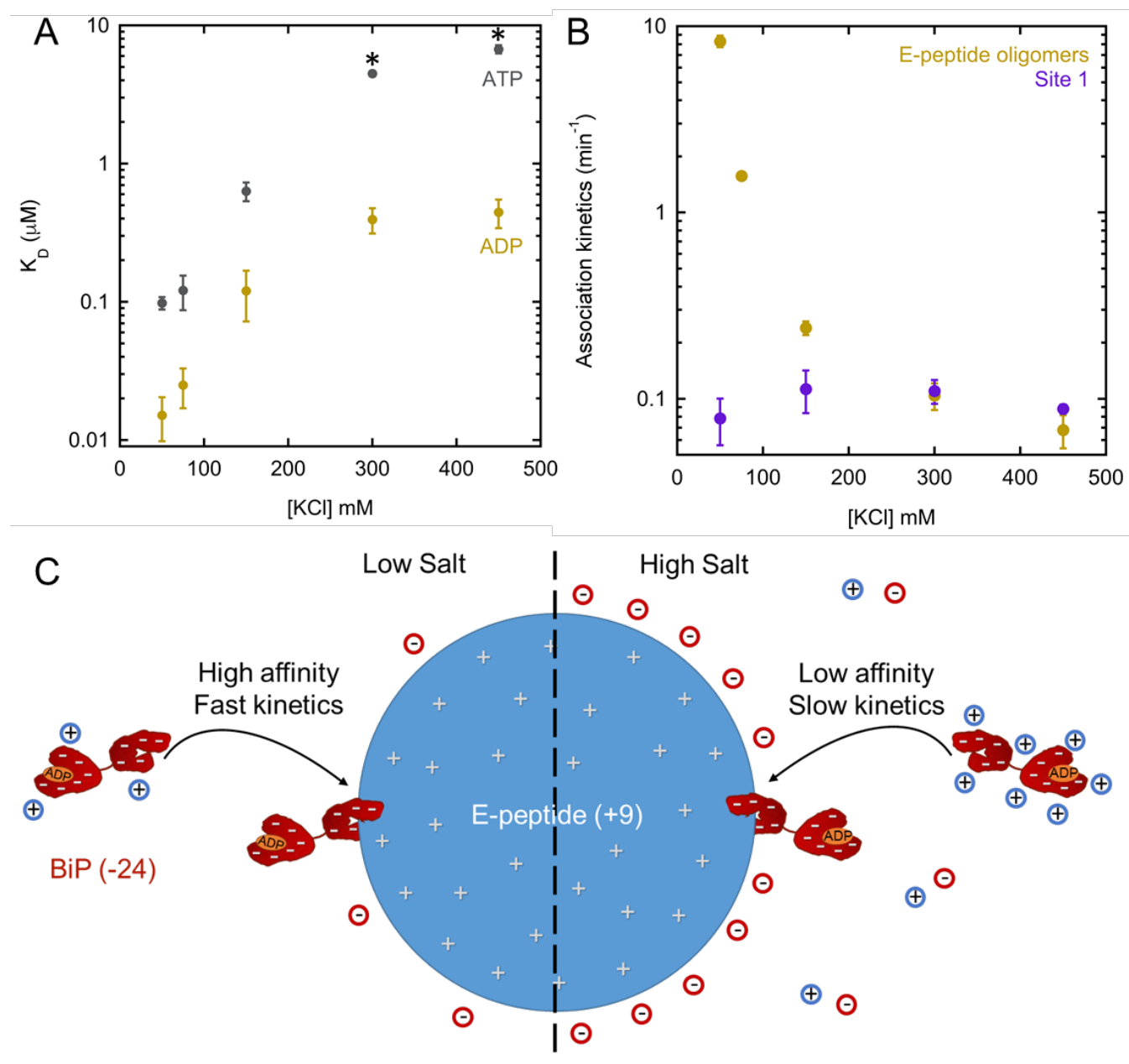

Figure 4. Influence of salt on BiP binding E-peptide oligomers. (A) Salt dependence of $K_{D}$ for BiP binding E-peptide as measured by $\mathrm{BiP}_{\mathrm{SBD}}$ FRET assay in the presence of ADP or ATP. Individual binding curves shown in Supplemental Figure 8A\&B. Asterisks indicate lower confidence of fitting, as described in Supplemental Figure 8B. (B) Salt dependence of association kinetics between BiP and $0.1 \mu \mathrm{M} \mathrm{E}-$

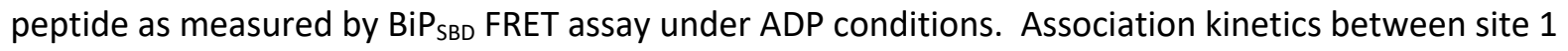
and $0.1 \mu \mathrm{M}$ BiP was determined by FP (Methods). (C) Model for BiP's salt-dependent binding of Epeptide oligomers. Negative charge for BiP and positive charge for E-peptide is shown as grey dashes and grey plus-signs, respectively. Counterions to E-peptide and BiP are shown as negatively-charged red circles and positively-charged blue circles, respectively.

Given the dramatic influence of salt on the affinity of BiP to E-peptide oligomers, we questioned whether electrostatic steering, which is characterized by salt-dependent association rates leading to salt-dependent binding affinity, is the underlying cause. At low salt BiP binding is indeed accelerated and we therefore performed the measurements at $10^{\circ} \mathrm{C}$ to slow the kinetics such that they can be quantified over a large range of rates. Figure $4 \mathrm{~B}$ shows salt-dependent association rates between BiP and E-peptide in which association kinetics decrease by 100 -fold between 50 to $450 \mathrm{mM} \mathrm{KCl}$. In comparison, Site 1 has no salt-dependent changes in association rates and converges with E-peptide 
association rates at high salt. Collectively, the above results indicate that electrostatic steering enhances BiP affinity for prolGF2 and E-peptide oligomers (Figure 4C).

\section{Two energetic contributions to BiP binding to E-peptide oligomers}

Comparing the salt-dependent affinity of BiP to E-peptide oligomers versus its affinity for monomeric peptides (Figure 5A) shows that two distinct energetic contributions underpin BiP's high affinity for Epeptide oligomers. BiP binds sites 1-3 with minimal salt-dependence, even though binding sites 2 and 3 are positively charged. This lack of salt dependence is also observed for the extended fragments centered at site 1 (residues 92-120 and 92-139). Importantly, BiP's affinity for E-peptide oligomers at high salt matches that of all the monomeric fragments that include site 1 . This suggest that two energetic contributions enable BiP to bind the E-peptide oligomers with high affinity. The first contribution is from the typical binding affinity between BiP and site 1 , and the second contribution is from electrostatic attraction between BiP and the E-peptide oligomer. As the electrostatic contribution is screened by salt BiP's affinity for E-peptide oligomers converges to the measured affinities of all constructs that contain site 1 .

The data in Figure 5A enables the electrostatic contribution to binding to be determined at any salt concentration. For example, under ADP conditions and at $50 \mathrm{mM} \mathrm{KCl} B i P$ binds E-peptide oligomers with $\sim 60$-fold higher affinity than to site $1\left(K_{D}=0.015 \pm 0.005 \mu \mathrm{M}\right.$ compared to $\left.K_{D}=0.95 \pm 0.17 \mu \mathrm{M}\right)$. A similar analysis under ATP conditions shows that electrostatic attraction provides a 130 -fold enhancement of affinity of BiP to E-peptide oligomers at $50 \mathrm{mM} \mathrm{KCl}$ (Supplemental Figure 9). While the influence of salt has a dramatic influence on BiP binding oligomers, only minor effects are observed for $\mathrm{BiP}$ binding the monomeric site 1 peptide. For example, increasing salt provides a slight enhancement of site 1 binding under ADP conditions ( $K_{D}$ of $0.95 \pm 0.17 \mu \mathrm{M}$ at $50 \mathrm{mM} \mathrm{KCl}$ versus $0.46 \pm 0.05 \mu \mathrm{M}$ at 450 $\mathrm{mM} \mathrm{KCl}$ ), and no salt-dependent affinity changes are observed under ATP conditions (Supplemental Figure 9). The agreement between the affinities measured indirectly using $\mathrm{BiP}_{\mathrm{SBD}}$ FRET assay and directly using FP at high salt confirms that the $\mathrm{BiP}_{S B D}$ FRET measurements provide a reliable measurement of client affinity.

Theoretical predictions (see Chapter 9 in Physical Biology Of The Cell ${ }^{28}$ ) and experiments on viral capsids $^{29}$ provide a quantitative framework for understanding the influence of salt on electrostatic screening around large macromolecular assemblies. In particular, the free energy contribution of electrostatics from charged spherical assemblies should vary linearly with the square root of the salt concentration. Figure 5B shows the electrostatic contribution to BiP binding free energy of BiP versus the square root of the salt concentration. We indeed observe this expected linear relationship up until the point at which the electrostatics no longer contribute to binding (when $\Delta G_{\text {elec }}^{o}=0$ ). While other factors may also contribute to the binding of BiP to E-peptide oligomers, our data is consistent with a model in which two energetic factors predominate. The first is the foundational hydrophobic interactions between BiP and site 1 , which has the characteristically weak affinity of $\sim 1 \mu \mathrm{M}$ and a minimal salt dependence. The second is the electrostatic contribution that is unique to the oligomerized the E-peptide and obeys the strong salt dependence predicted by electrostatic screening. 

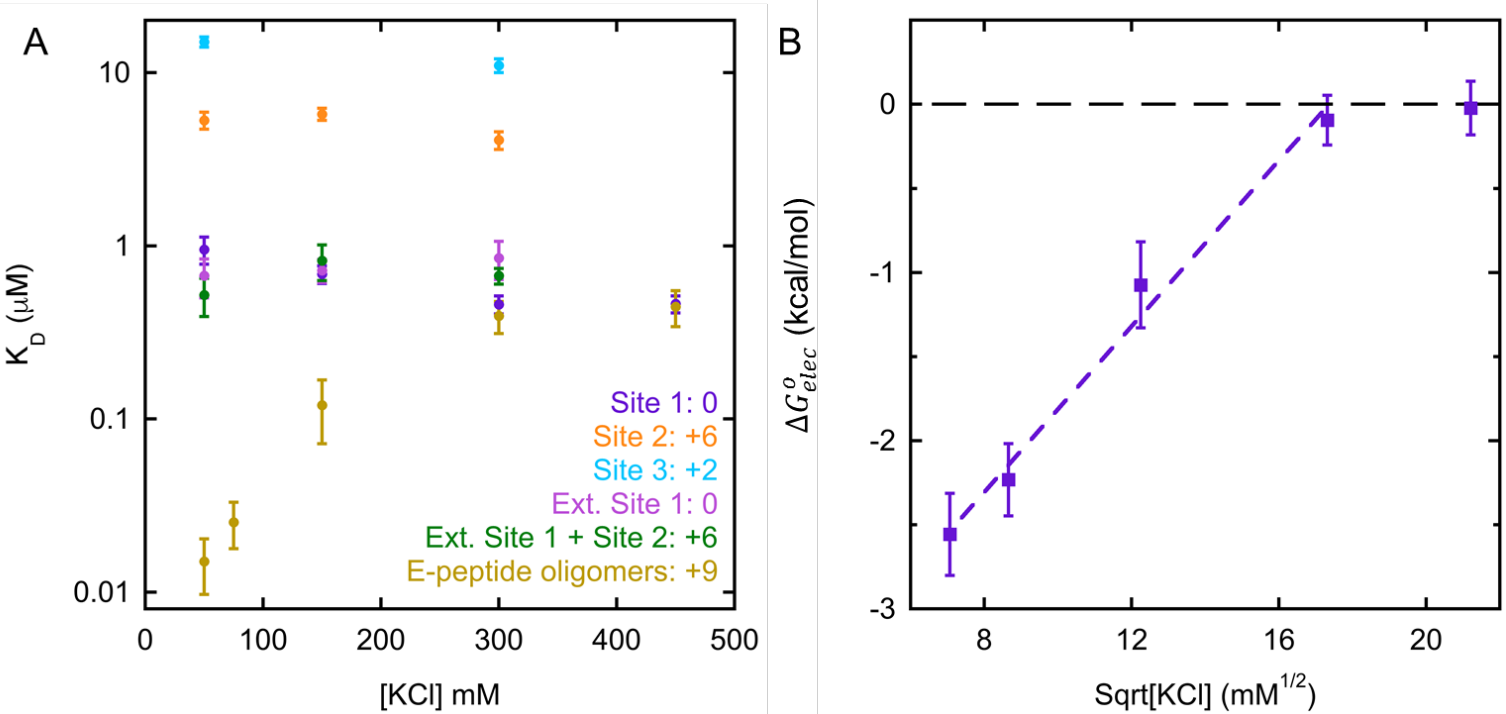

Figure 5. Compilation of BiP's affinity for E-peptide and binding sites in presence of increasing salt concentrations. (A) Affinities of monomeric E-peptide fragments and the oligomeric E-peptide. Net charge of each fragment is indicated next to name. Error bars are the SEM for at least three binding curve replicates. (B) Electrostatic contribution as calculated by $\Delta G_{\text {elec }}^{o}=-\mathrm{RT} \ln \left(\mathrm{K}_{\mathrm{D}, \text { site } 1} / \mathrm{K}_{\mathrm{D}, \mathrm{E}-\text {-peptide oligomers }}\right)$, which is screened out by increasing salt ${ }^{28}$. Error bars are the propagated uncertainty from panel $A$. The $\mathrm{K}_{\mathrm{D} \text {,site } 1}$ value at $50 \mathrm{mM} \mathrm{KCl}$ is used to calculate $\Delta G_{\text {elec }}^{o}$ at both 50 and $75 \mathrm{mM} \mathrm{KCl}$. Purple dashed line indicates linear fit ( $\Delta G_{\text {elec }}^{o}$ intercept: $-4.3 \pm 0.2 \mathrm{kcal} / \mathrm{mol}$ and slope: $0.25 \pm 0.02$ ). Black dashed line indicates $\Delta G_{\text {elec }}^{o}=0$.

\section{The electrostatic driving force that favors BiP binding E-peptide oligomers is widely dispersed across the E-peptide sequence}

E-peptide oligomers provide a favorable electrostatic contribution for BiP biding despite the fact that primary binding site on the E-peptide (site 1 ) has no net-charge. Thus, we expect that E-peptide variants containing site 1, but with lower net charge will have lower affinity for BiP. Recall that the E-peptide has clusters of positively charged residues at conserved endoprotease cut sites (Figure 1B). Therefore, we designed a series of truncations to successively remove each of these +3 charge clusters to determine whether a single charge cluster dominates or whether each cluster contributes equally (Figure 6A). In these experiments $\mathrm{BiP}$ is maintained at a low concentration, and the E-peptide constructs are titrated to enable oligomerization. Figure $6 \mathrm{~B}$ shows a progressive enhancement of BiP affinity for E-peptide oligomers that are assembled from E-peptide constructs with progressively positive net charge. This trend (dashed lines, Figure 6B) shows a convergence of the high affinity binding of BiP to E-peptide oligomers to low affinity site 1 binding as the net charge on E-peptide constructs is reduced. This convergence is conceptually similar to the convergence in oligomer and site 1 affinities with increasing salt (Figure 6B). In both cases, negatively-charged BiP's electrostatic targeting towards positivelycharged E-peptide oligomers is screened physically by removing net charge from the E-peptide by way of truncations or by increasing the salt concentration. 
A

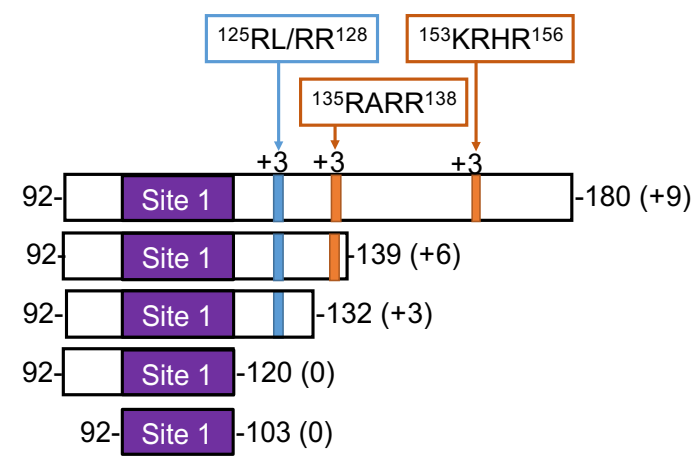

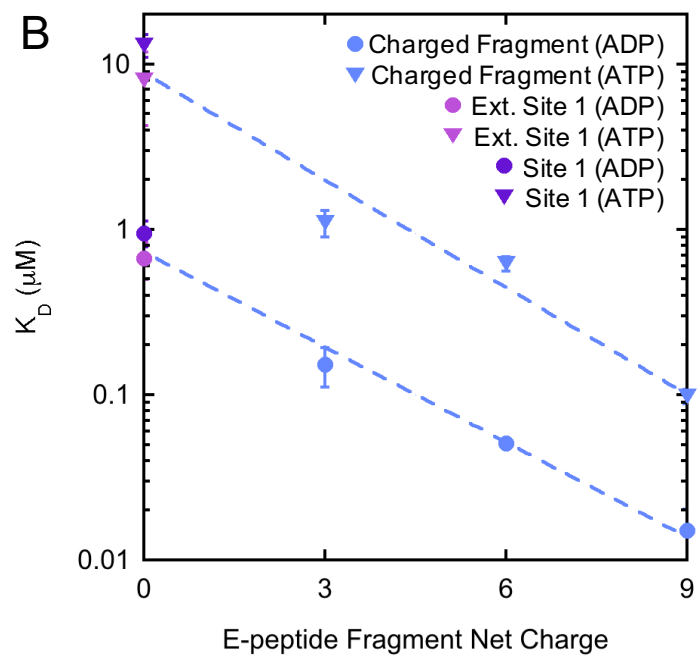

Figure 6. BiP's interactions with E-peptide and E-peptide truncations of decreasing net charge. (A) Epeptide and E-peptide truncations with net charge and endoprotease cut sites are indicated for each construct. (B) BiP's $K_{D}$ for each E-peptide fragment listed in A, as a function of fragment's net charge. $K_{D}$ data is from $\mathrm{BiP}_{\mathrm{SBD}} \mathrm{FRET}$, except for Ext. Site 1 and Site 1 which are from FP data. Error bars indicate SEM for 3 replicates, and error bars may be smaller than data point. Dashed lines indicate a logarithmic fit ( $\mathrm{K}_{\mathrm{D}}$ intercepts: $\left.0.73 \pm 0.10 \mu \mathrm{M}(\mathrm{ADP}) ; 8.9 \pm 2.6 \mu \mathrm{M}(\mathrm{ATP})\right)$. Slopes are: $10^{-(0.19 \pm 0.01) x}(\mathrm{ADP}) ; 10^{-(0.22 \pm 0.03) x}$ (ATP), where $x$ is the net charge of E-peptide fragment and the uncertainty is from the fitting error.

\section{Discussion}

The action of Hsp70-type chaperones on aggregates, oligomers, and fibrils is a crucial aspect of cellular homeostasis, the adaptive response to environmental stress, and the progression of age-related diseases $^{30}$. However, heterogeneity of aggregates, oligomers, and fibrils imposes technical challenges in determining how Hsp70s recognize oligomeric client states versus the monomeric peptide fragments that are often used as model systems to study Hsp70:client binding. Here, by dissecting the mechanism by which BiP recognizes prolGF2 and E-peptide oligomers, we discover that electrostatic attraction is a powerful driving force that enables BiP to preferentially bind oligomeric client states. BiP binds Epeptide oligomers with nanomolar affinity, but binds the monomeric constituent peptides with micromolar affinity. In this regard BiP interacts very differently with prolGF2 oligomers compared to the well-studied $C_{H} 1$ domain in which BiP binds full-length $C_{H} 1\left(K_{D}\right.$ of $\left.4.2 \mu \mathrm{M}\right)$ with similar affinity to its constituent peptide motif $\left(K_{D} \text { of } 12 \mu \mathrm{M}\right)^{21,31}$. The predominant BiP binding site on prolGF2 is located at the preptin hormone region of the E-peptide (site 1, Figure $3 \mathrm{~A}$ ), a region that does not fold ${ }^{32}$. This again contrasts with the BiP recognition of $\mathrm{C}_{\mathrm{H}} 1$, in which the BiP binding site is buried after $\mathrm{C}_{\mathrm{H}} 1$ folds and forms a disulfide-linked complex with $\mathrm{C}_{\mathrm{L}}{ }^{31}$. The preptin region binds non-specifically to BSA (Supplemental Figure 7), suggesting a functional role for $\mathrm{BiP}$ in protecting this region from non-productive interactions in the ER.

A strong electrostatic driving force causes BiP to preferentially bind oligomers. This is evident in the saltdependent affinity of BiP to E-peptide oligomers but not to the constituent monomeric peptides (Figure $5 A)$. The energetic contribution from electrostatic screening varies with the square root of the salt 
concentration (Figure 5B), as predicted theoretically ${ }^{28}$, and measured experimentally in the assembly of viral capsids ${ }^{29}$. The electrostatic affinity enhancement, spanning approximately two orders of magnitude, is reflected in the weakening influence of successive truncations that remove charge from the E-peptide (Figure 6B), and the salt-dependent association rate of BiP binding E-peptide oligomers (Figure 4B). Such salt-dependent association kinetics are characteristic of electrostatic steering between large highly charged complexes as with the positively charged multimeric Von Willebrand factor binding its negatively charged receptor glycoprotein $\mathrm{Ib}^{33}$. In this case, the association kinetics span approximately two orders of magnitude between 80 to $500 \mathrm{mM}$ salt ${ }^{33}$, a similar magnitude as what we observe for BiP binding E-peptide oligomers (Figure 4B).

The electrostatic explanation underlying BiP's high affinity for oligomers provides a plausible explanation for why Hsp70 chaperones interact with certain aggregated client proteins with high affinity. Figure 7 is a compilation of previously measured $\mathrm{Hsp} 70$ affinities for monomeric and oligomeric clients, evaluated by the predicted net charge of the client (data and references are in Supplemental Table 1). Hsp70s bind peptides with a maximal affinity of $\sim 1 \mu \mathrm{M}$. Even engineered peptides that are designed to have high affinity for Hsp70, such as the Javelin sequence, only reach $\sim 1 \mu \mathrm{M}^{34}$. A similar upper limit appears to apply to Hsp70 binding negatively charged clients such as $\alpha$-synuclein (net charge of -9 ) irrespective of whether it is monomeric or oligomeric $\left(\mathrm{K}_{\mathrm{D}} \sim 10 \mu \mathrm{M}\right)^{8}$. Clathrin is a second example of a negatively charged (net charge -64) oligomer, which Hsp70 also binds with low affinity $\left(K_{D} \sim 3 \mu \mathrm{M}\right)^{26}$.

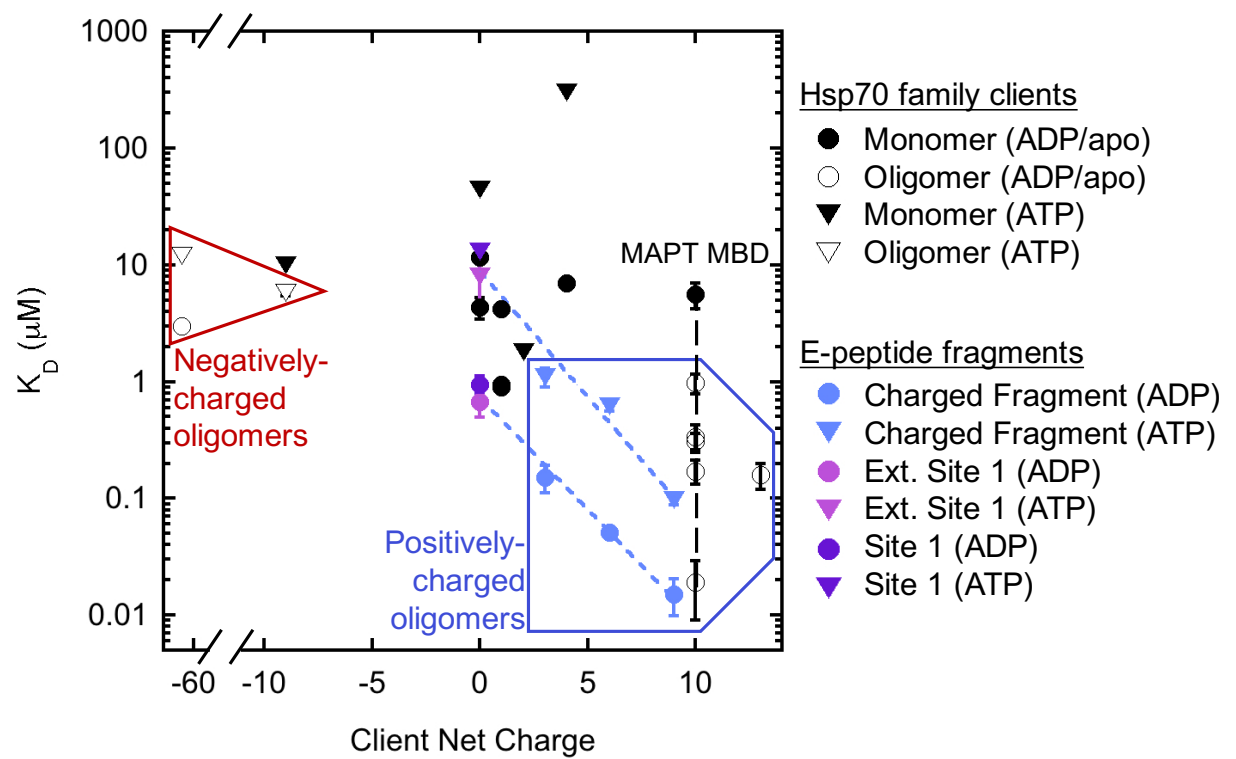

Figure 7. Compilation of $\mathrm{Hsp} 70$ and BiP dissociation constants to monomeric and oligomeric clients, sorted by net charge. See Supplemental Table 1 for data and references. Black dashed line indicates MAPT MBD $K_{D}$ values with increasing size (1-2mer to fibril $\left.{ }^{7}\right)$. $K_{D}$ data for E-peptide, E-peptide truncations, and associated blue dashed lines are from Figure 6.

To our knowledge the only reported instances of Hsp70 binding with much higher affinity than $\sim 1 \mu \mathrm{M}$ is in the case of aggregates of positively charged clients. For example, the binding of cytosolic Hsp70 (net 
charge -11) to MAPT MBD (net charge +10) is directly proportional to the size of the oligomer size, with larger oligomers yielding higher affinities (Figure 7, black dashed line). Hsp70 binds MAPT MBD fibrils with $\sim 10 \mathrm{nM}$ affinity ${ }^{7}$, a value comparable to BiP affinity to E-peptide oligomers. A fast association rate is observed between $\mathrm{Hsp70}$ and MAPT MBD 7 raising the possibility that electrostatic steering is at work, similar to our findings with BiP and E-peptide oligomers (Figure 4B). The affinity of BiP to E-peptide oligomers, as well as E-peptide truncations with different net charges (blue diagonal dashed lines, Figure 7) all fall within the range of values measured for other positively charged clients. The data in Figure 7 is restricted to metazoan Hsp70s, however experiments with the bacterial Hsp70 homolog DnaK (net charge -30) suggest that this mechanism also applies. Specifically, DnaK has been reported to bind positively charged IAPP oligomers in the pM-range ${ }^{35}$. However, the affinity of DnaK for oligomers may not be directly comparable to metazoan Hsp70 data in Figure 7, because DnaK can bind monomeric peptides with ten-fold higher affinity than is observed for metazoan Hsp70s (Supplemental Table 2).

The idea that electrostatics target Hsp70s to positively charged oligomeric clients, provides predictions for future experiments. For example, the MAPT $3 R$ and $4 R$ isoforms, which also have a positive net charge, exhibit high affinity binding to Hsp70 (Supplemental Table 1) but their oligomerization state has not been determined ${ }^{36}$. The electrostatic explanation predicts that MAPT $3 R$ and $4 R$ isoforms should be oligomeric. In the case of IGF proteins, electrostatics should favor the binding of BiP to oligomeric states of prolGF1 (net charge +18 ), but not proinsulin (net charge -3 ). One additional area for future investigation is to better understand the role of oligomer size heterogeneity on BiP affinity. While Hsp70 affinity for the MAPT MBD is proportional to the oligomer size (Figure 7, black dashed line) more detailed measurements are needed to determine if a similar relationship holds for BiP binding to Epeptide and prolGF2 oligomers.

Our findings have implications for how the ER responds to stress. A current model for the unfolded protein response (UPR) activation involves BiP binding to the luminal portion of key transmembrane proteins (IRE1 and PERK) that are held inactive when BiP is bound ${ }^{37}$. In this model, when the concentration of unfolded protein gets sufficiently high BiP will favor binding the client proteins rather than the UPR transmembrane proteins. Our results suggests that oligomerized clients within the ER could displace BiP from the UPR receptors due to the relatively high affinity of BiP towards oligomers. Thus, our results suggest that the UPR may be initiated by protein oligomerization/aggregation that could be independent of a rise in the concentration of unfolded proteins.

\section{Methods}

\section{Bioinformatics}

Predicted BiP-binding motifs on prolGF2 were calculated with BiPPred ${ }^{27}$. BiPPred calculates a predicted BiP-binding score for a 7-residue motif, and an average BiPPred score for each residue is calculated and plotted in Figure 3A. Net charge is calculated from sum of $-(\mathrm{Asp}+\mathrm{Glu})+(\mathrm{Lys}+\mathrm{Arg})$ residues.

\section{Protein purification}

6-his tagged BiP was purified via Ni-NTA affinity chromatography, and 6-his tag was cleaved with TEV. Subsequent Ni-NTA affinity chromatography removed 6-his tag and TEV, anion-exchange 
chromatography removed nucleotide bound to BiP, and BiP was buffer exchanged with size-exclusion chromatography. BiP was stored in $25 \mathrm{mM}$ Tris pH 7.5, $50 \mathrm{mM} \mathrm{KCl}, 1 \mathrm{mM} \mathrm{DTT}$, and 2\% glycerol.

ProlGF2, E-peptide, E-peptide 92-139, E-peptide 92-120, and mature IGF2 were purified from inclusion bodies. E-peptide, E-peptide 92-139, and E-peptide 92-120 contained an N-terminal 6-histidine tag and cysteine mutation at Ser95 for FITC labeling. Briefly, inclusion bodies were washed and insoluble protein was denatured in an $8 \mathrm{M}$ urea, $25 \mathrm{mM}$ Tris buffer containing reducing agent TCEP. Protein was purified by ion-exchange chromatography and/or Ni-NTA affinity chromatography in denaturing conditions. Proteins used in FP assays were labeled with FITC-maleimide. Proteins were stored denatured in buffer containing $8 \mathrm{M}$ urea.

BiP-binding sites 1 and 3 were synthesized by Alan Scientific (Gaithersburg, MD) and site 2 was synthesized by Genscript (Piscataway, NJ). All peptides are N-terminally labeled with FITC via an amino hexanoic acid linker. For FITC-Mature-1cys, mature IGF2 was mutated to remove all cysteines except C70, which was labeled with FITC.

\section{Fluorescence depolarization}

$50 \mathrm{nM}$ FITC-labeled BiP D27C or BiP NBD D27C was incubated with buffer containing $25 \mathrm{mM}$ MES pH 6.0, $50 / 150 / 300 \mathrm{mM} \mathrm{KCl}, 1 \mathrm{mM} \mathrm{MgCl} 2,1 \mathrm{mM}$ nucleotide (ADP or ATP), $0.5 \mathrm{mg} / \mathrm{mL} \mathrm{BSA}$, and $1 \mathrm{mM}$ DTT until polarization values reached equilibrium, for about 30 minutes, at $37^{\circ} \mathrm{C}$. Experiments were also conducted in the absence of BSA, when noted. Clients were added directly from purified $8 \mathrm{M}$ urea stock, except prolGF2 (diluted out of denaturant 1:10 in $50 \mathrm{mM} \mathrm{MES} \mathrm{pH} \mathrm{6.0,} 2 \mathrm{mM}$ TCEP and incubated 20-30 minutes). Fluorometer setup had an excitation wavelength at $492 \mathrm{~nm}$ and emission wavelength at $520 \mathrm{~nm}$ with $6 \mathrm{~nm}$ slit widths, and 1 second integration time.

FP experiments containing FITC-labeled BiP-binding site peptides used $50 \mathrm{nM}$ of labeled peptides, except for FITC-Mature-1cys (57.5 nM). For ATP experiments, FITC-labeled peptide was added to BiP preincubated for 20 minutes in a buffer containing $25 \mathrm{mM}$ buffer (MES or Tris), 50/150/300 mM KCl, $1 \mathrm{mM}$ $\mathrm{MgCl}_{2}, 1 \mathrm{mM}$ ATP, $0.5 \mathrm{mg} / \mathrm{mL} \mathrm{BSA}$, and $1 \mathrm{mM}$ DTT at $37^{\circ} \mathrm{C}$. For ADP experiments, contaminating amounts of ATP were removed from $1 \mathrm{mM}$ ADP with 0.005 units hexokinase, $1 \mathrm{mM}$ glucose, and $5 \mathrm{mM}$ $\mathrm{MgCl}_{2}$ and incubated 1 hour at $37^{\circ} \mathrm{C}$. Polarization measurements for FITC-E-peptide 121-139 were taken with excitation at $493 \mathrm{~nm}$, emission at $522 \mathrm{~nm}, 5 \mathrm{~nm}$ slit widths, and a 1 second integration time. Polarization measurements with FITC-E-peptide 103-120 and FITC-E-peptide 151-169 used $493 \mathrm{~nm}$ excitation wavelength, $518 \mathrm{~nm}$ emission wavelength, and $6 \mathrm{~nm}$ slit widths. FP experiments with FITC-Epeptide 92-120 or FITC-E-peptide 92-139 had an excitation wavelength of $492 \mathrm{~nm}$ and emission wavelength of $522 \mathrm{~nm}$.

$K_{D}$ values were calculated using the single-site binding equation,

$$
P=\frac{a[\text { client }]}{K_{D}+[\text { client }]}+c
$$

where $P$ is polarization, $a$ is the polarization amplitude and $c$ is the polarization value in the absence of client. Association kinetics for $0.1 \mu \mathrm{M}$ BiP to site 1 (Figure $4 \mathrm{~B}$ ) was determined by a linear extrapolation 
of association kinetics measured over the complete range of BiP concentrations from Supplemental Figure 4A.

\section{FRET}

For the BiP-BiP FRET assay, in separate reactions, BiP was labeled with donor (AlexaFluor $555 \mathrm{C}_{2}$ maleimide) or acceptor (AlexaFluor $647 \mathrm{C}_{2}$ maleimide) fluorophores. $25 \mathrm{nM}$ donor-labeled BiP and 25 $\mathrm{nM}$ acceptor-labeled BiP were incubated until FRET efficiency reached equilibrium, about 20-30 minutes, in buffer containing $25 \mathrm{mM}$ MES pH 6.0, $50 \mathrm{mM} \mathrm{KCl}, 1 \mathrm{mM} \mathrm{ADP}, 0.5 \mathrm{mg} / \mathrm{mL}$ BSA, and $1 \mathrm{mM}$ DTT at $37^{\circ} \mathrm{C}$. ADP was pretreated with 0.005 units hexokinase, $1 \mathrm{mM}$ glucose, and $5 \mathrm{mM} \mathrm{MgCl}_{2}$ for 1 hour at $37^{\circ} \mathrm{C}$. Clients were added in the same manner used in FP experiments. Fluorometer setup had donor excitation wavelength at $532 \mathrm{~nm}$, donor emission wavelength at $567 \mathrm{~nm}$, and an acceptor emission wavelength at $668 \mathrm{~nm}$, and $6 \mathrm{~nm}$ slit widths. FRET efficiency (E) was calculated by the donor (D) and acceptor (A) emission fluorescence:

(Equation 2)

For the BiPSBD $F R E T$ assay, a previously described BiP double mutant $\mathrm{G} 518 \mathrm{C}$ and $\mathrm{Y} 636 \mathrm{C}$ was simultaneously labeled with donor and acceptor fluorophores, AlexaFluor $555 \mathrm{C}_{2}$ maleimide and AlexaFluor $647 \mathrm{C}_{2}$ maleimide, respectively ${ }^{21}$. In the BiPSBD FRET assay, the value of the FRET efficiency is therefore limited to a value of 0.5 because at most only $50 \%$ of the BiP molecules can be labeled with one donor and one acceptor fluorophore. BiP was diluted to $50 \mathrm{nM}$ into buffer containing $25 \mathrm{mM} \mathrm{MES}$ $\mathrm{pH}$ 6.0, 50/150/300/450 mM KCl, $1 \mathrm{mM} \mathrm{MgCl}, 1 \mathrm{mM} \mathrm{ATP,} 0.5 \mathrm{mg} / \mathrm{mL}$ BSA, and $1 \mathrm{mM} \mathrm{DTT}$. Experiments with ADP contained $1 \mathrm{mM}$ ADP. If indicated, hexokinase-treated ADP was incubated as above experiments. Experiments with $5 \%$ ATP had $1 \mathrm{mM} \mathrm{ADP}$ and $0.05 \mathrm{mM}$ ATP and were completed at 50 $\mathrm{mM} \mathrm{KCl}$. Fluorometer setup had a donor excitation wavelength at $532 \mathrm{~nm}$, donor emission wavelength at $567 \mathrm{~nm}$, and acceptor emission wavelength at $668 \mathrm{~nm}, 4 \mathrm{~nm}$ slit widths, and 0.5 second integration time. $K_{D}$ values were calculated using a single-site binding equation,

$$
E=\frac{a[\text { client }]}{K_{D}+[\text { client }]}+c
$$

(Equation 3)

where $a$ is the FRET efficiency amplitude and $c$ is the FRET efficiency value in the absence of client. $K_{D}$ values $<0.2 \mu \mathrm{M}$ were determined via

$$
E=c+a \frac{\left[B+x+K_{D}\right]-\sqrt{\left[B+x+K_{D}\right]^{2}-4[B] x}}{2[B]}
$$

where $x$ is the concentration of client E-peptide, $K_{D}$ is the dissociation constant between BiP and client, and $B$ is the concentration of $\mathrm{BiP}_{\mathrm{SBD}}$ FRET-labeled protein used in experiments.

\section{Light scattering}

ProlGF2 and E-peptide were assayed for light scattering with an absorbance at $320 \mathrm{~nm}$ at $25^{\circ} \mathrm{C}$.

Background was subtracted at $700 \mathrm{~nm}$. $2 \mu \mathrm{M}$ of each protein was prepared in buffer containing $25 \mathrm{mM}$ 
481 MES pH 6.0, $1 \mathrm{mM} \mathrm{MgCl} 2,1 \mathrm{mM}$ ATP, $0.3 \mathrm{mM}$ TCEP. Immediately before assay, prolGF2 was diluted out 482 of urea into buffer containing $50 \mathrm{mM}$ MES pH 6 and $2 \mathrm{mM}$ TCEP.

483 Dynamic light scattering

484 DLS data was obtained using a DLS/SLS-5022F from ALV (ALV-Laser Vertriebsgesellschaft m.b.H.) coupled 485 with a $22 \mathrm{~mW}$ HeNe Laser from JDS Uniphase Corporation. E-peptide and prolGF2 were diluted into 50 $486 \mathrm{mM} \mathrm{MES} \mathrm{pH} \mathrm{6.0,50} \mathrm{mM} \mathrm{KCl,} 2 \mathrm{mM} \mathrm{TCEP}, 1 \mathrm{mM} \mathrm{MgCl}_{2}$, and $1 \mathrm{mM}$ ATP. 10 rounds of 20 seconds were 487 used for data collection at $25^{\circ} \mathrm{C}$. Protein sample was monitored at $90^{\circ}$ by laser light scattering at 630 $488 \mathrm{~nm}$. Size-distribution analysis from an intensity correlation function was used to attain $\mathrm{R}_{\mathrm{H}}{ }^{38}$.

$489 \quad$ ATPase assay

490 ATPase activity was measured by depletion of NADH via an enzyme-linked assay with pyruvate kinase 491 and lactose dehydrogenase. $2 \mu \mathrm{M}$ BiP was assayed in $25 \mathrm{mM} \mathrm{MES} \mathrm{pH} \mathrm{6.0,} 50 \mathrm{mM} \mathrm{KCl}, 1 \mathrm{mM} \mathrm{MgCl}, 1$ $492 \mathrm{mM}$ ATP, $1 \mathrm{mM} \mathrm{DTT}, 0.5 \mathrm{mM} \mathrm{NADH}, 0.5 \mathrm{mM}$ PEP, $0.1 \mu \mathrm{M}$ pyruvate kinase, $0.1 \mu \mathrm{M}$ lactose 493 dehydrogenase, and $2.5 \mu \mathrm{M}$ client protein at $37^{\circ} \mathrm{C}$. NADH depletion was monitored at an absorbance of $494340 \mathrm{~nm}$. ATPase rates reported are an average of 3 measurements, and the error is the SEM.

495

496

\section{Acknowledgements}

497 We thank Linda Hendershot, Daniel Oprian, and Tijana Ivanovic for providing helpful feedback on the 498 results. Research for this project was supported by NIH R01 GM115356.

499

500

501 


\begin{tabular}{|l|l|l|l|}
\hline$[$ Salt $] \mathrm{mM}$ & $\mathrm{NaCl}, \mathrm{K}_{\mathrm{D}}(\mu \mathrm{M})$ & $\mathrm{KI}, \mathrm{K}_{\mathrm{D}}(\mu \mathrm{M})$ & $\mathrm{KCl}, \mathrm{K}_{\mathrm{D}}(\mu \mathrm{M})$ \\
\hline 50 & $0.0047 \pm 0.0022$ & $0.021 \pm 0.003$ & $0.015 \pm 0.005$ \\
\hline 300 & $0.29 \pm 0.03$ & $0.51 \pm 0.10$ & $0.39 \pm 0.08$ \\
\hline
\end{tabular}

503 Table 1. BiP dissociation constants for E-peptide using BiPSBD $F R E T$ assay with different salts, $\mathrm{NaCl}, \mathrm{KI}$, 504 and $\mathrm{KCl}$, in the presence of ADP.

505 


\section{Supplemental Figures \& Tables}
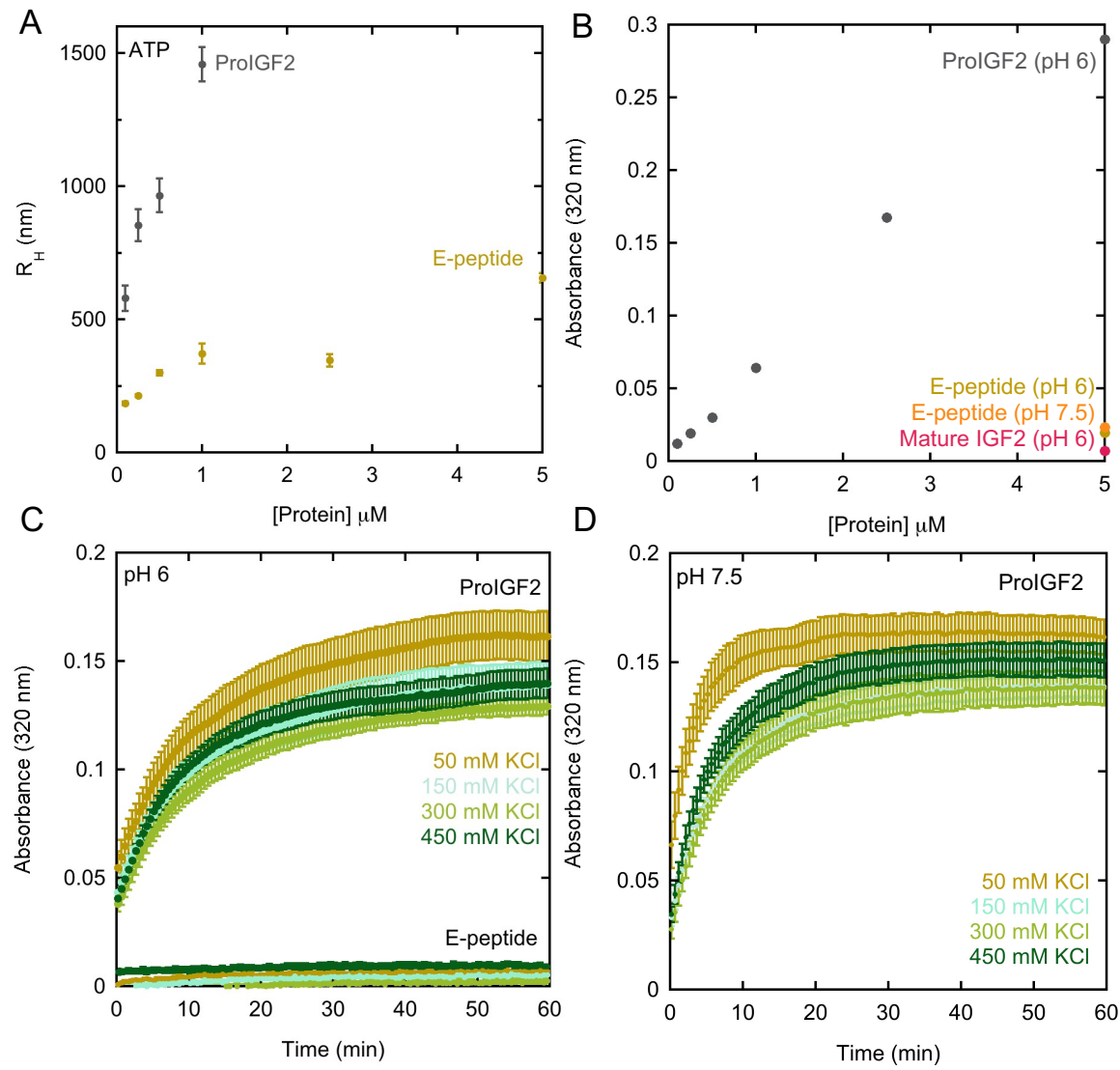

Supplemental Figure 1. ProlGF2, E-peptide, and mature IGF2 light-scattering (LS) data. (A) Average hydrodynamic radius $\left(R_{H}\right)$ of prolGF2 and E-peptide oligomers as measured by DLS. (B) Concentrationdependent LS data with prolGF2 shown with $5 \mu \mathrm{M}$ E-peptide and mature IGF2. (C) LS data with $2 \mu \mathrm{M}$ prolGF2 and E-peptide at pH 6 and increasing salt concentrations. Rates of prolGF2 LS at pH 6 with increasing $\mathrm{KCl}$ are $0.072 \pm 0.001,0.076 \pm 0.001,0.080 \pm 0.003$, and $0.091 \pm 0.001 \mathrm{~min}^{-1}$. (D) LS data with prolGF2 at pH 7.5 and increasing salt concentrations. Rates of prolGF2 LS at pH 7.5 with increasing $\mathrm{KCl}$ are $0.23 \pm 0.02,0.12 \pm 0.001,0.12 \pm 0.004$, and $0.14 \pm 0.004 \mathrm{~min}^{-1}$. Absorbance data was collected at $320 \mathrm{~nm}$ with a background subtraction of $700 \mathrm{~nm}$. Error bars indicate SEM for 3 replicates. 


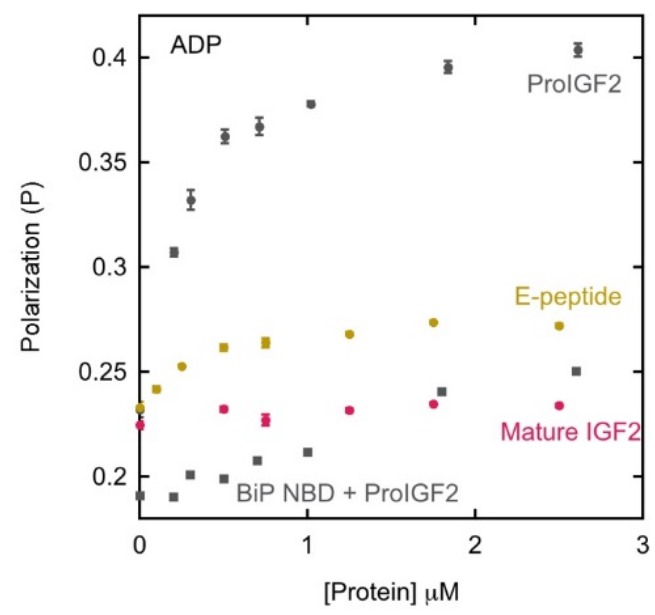

519

520 Supplemental Figure 2. FP data with FITC-BiP and prolGF2, E-peptide and mature IGF2 (circles) and 521 FITC-BiP NBD binding prolGF2 (squares) in ADP conditions. 


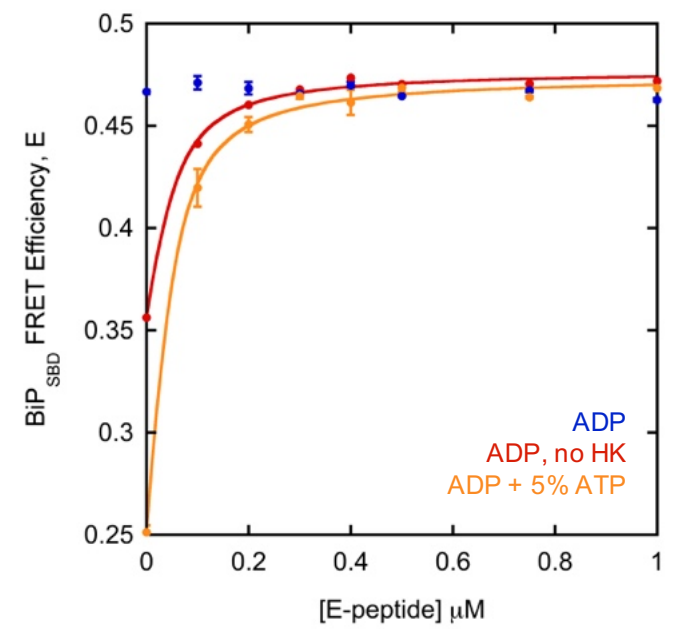

525 Supplemental Figure 3. BiP $P_{S B D}$ FRET efficiency in the presence of E-peptide with HK-treated ADP
526 (blue), ADP without an HK treatment (red, $K_{D}=0.015 \pm 0.005 \mu \mathrm{M}$ ) and ADP $+5 \%$ ATP (yellow, $K_{D}=$ $5270.019 \pm 0.004 \mu \mathrm{M})$. Solid line is fit to equation 4. Error bars indicate SEM for at least 3 replicates. 

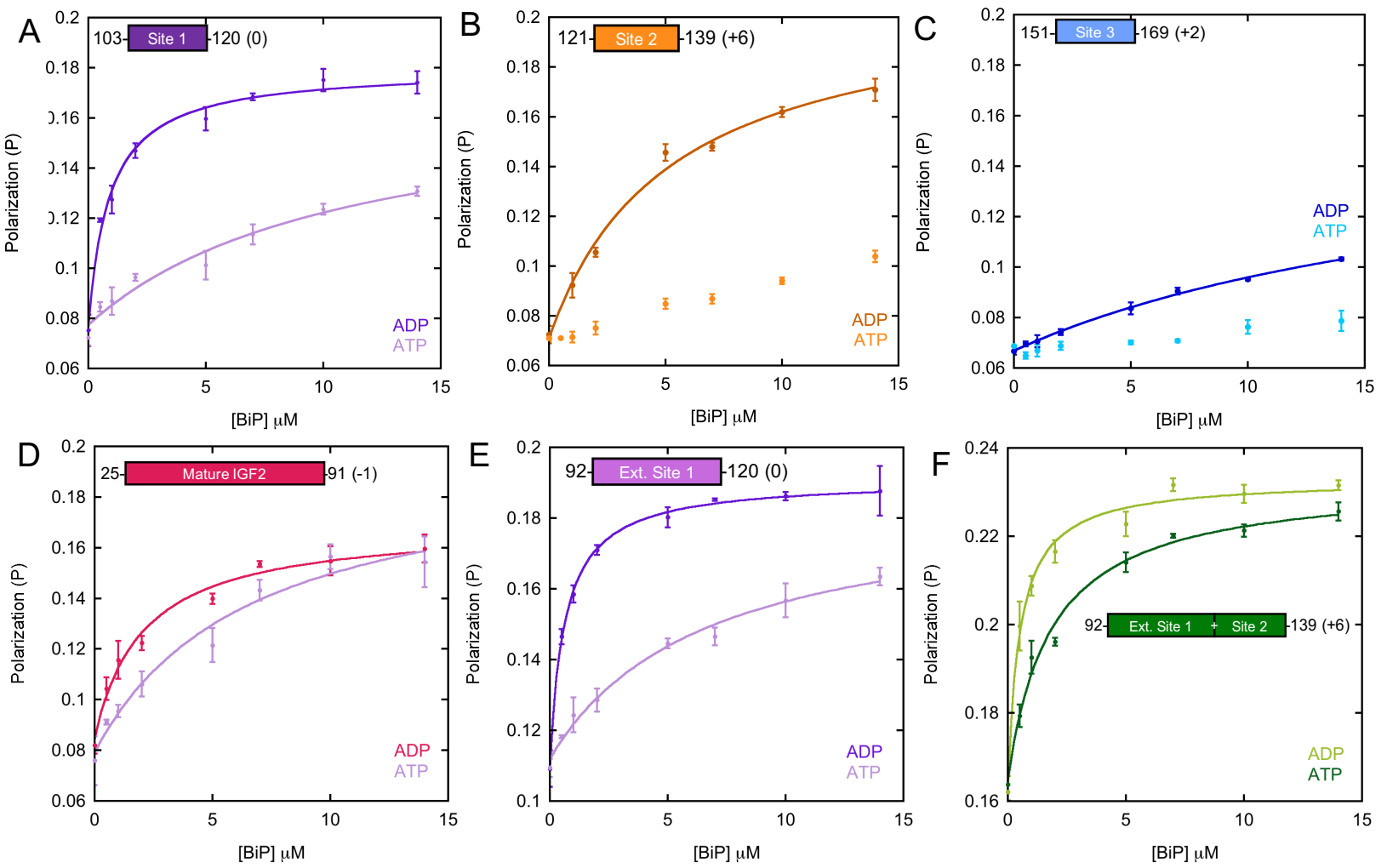

Supplemental Figure 4. FP BiP binding assay with FITC-labeled E-peptide fragments. Solid lines

532 indicate fit to equation 1 , in cases where $K_{D}$ values can be determined. (A) BiP affinity for site 1 is: $0.95 \pm$ $0.17 \mu \mathrm{M}$ and $13 \pm 2 \mu \mathrm{M}$, under ADP and ATP conditions respectively. $K_{D}$ under ATP conditions is determined using same maximum amplitude as ADP condition. (B) BiP affinity for site 2 is $5.3 \pm 0.6 \mu \mathrm{M}$ under ADP conditions. (C) BiP affinity for site 3 is $15 \pm 1 \mu \mathrm{M}$ under ADP conditions. (D) FP binding assay with FITC-labeled mature IGF $2^{1 \text { Cys }}$ and BiP in ADP and ATP states. Fit values as calculated from Equation 1 in the presence of ADP and ATP are $2.7 \pm 1.0$ and $9.7 \pm 4.5 \mu \mathrm{M}$, respectively. (E) BiP affinity for extended site 1 (residues 92-120) is: $0.67 \pm 0.17 \mu \mathrm{M}$ and $8.0 \pm 3.8 \mu \mathrm{M}$, under ADP and ATP conditions respectively. (F) BiP affinity for extended site $1 \& 2$ (residues 92-139) is: $0.52 \pm 0.13 \mu \mathrm{M}$ and $1.9 \pm 0.6 \mu \mathrm{M}$, under ADP and ATP conditions respectively. All error bars indicate SEM for three replicates. 
A

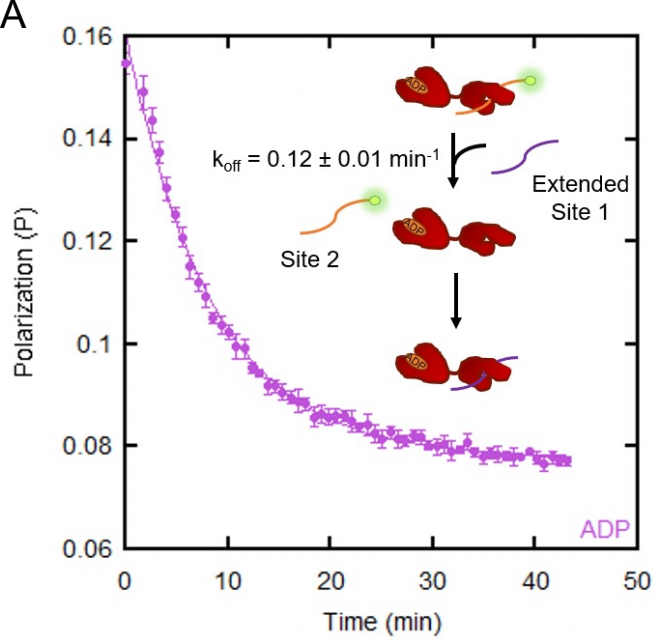

B

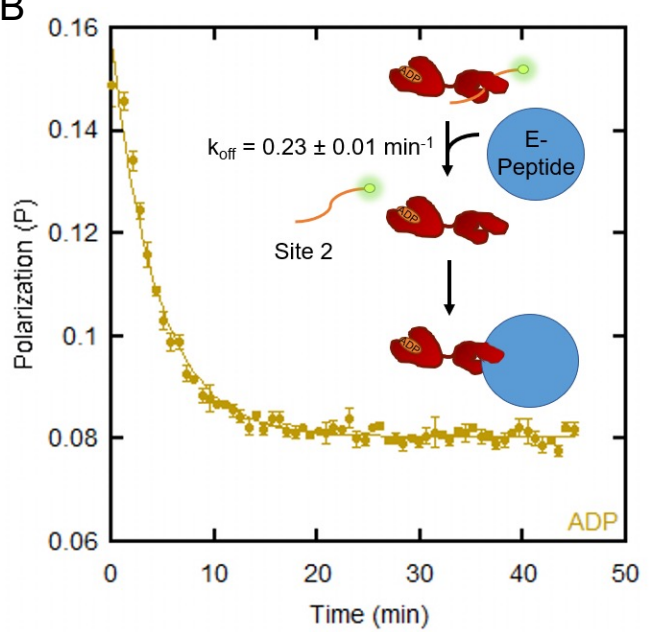

543

544

545

546

547

548

549

Supplemental Figure 5. Binding competition experiments. $50 \mathrm{nM}$ FITC-labeled site 2 was prebound to 5.3 $\mu \mathrm{M}$ BiP under ADP conditions. (A) Competition with $10 \mu \mathrm{M}$ of extended site 1. (B) Competition with $5.3 \mu \mathrm{M}$ of oligomerized E-peptide. Solid lines are a fit to an exponential decay. Error bars are the SEM for three replicates. 

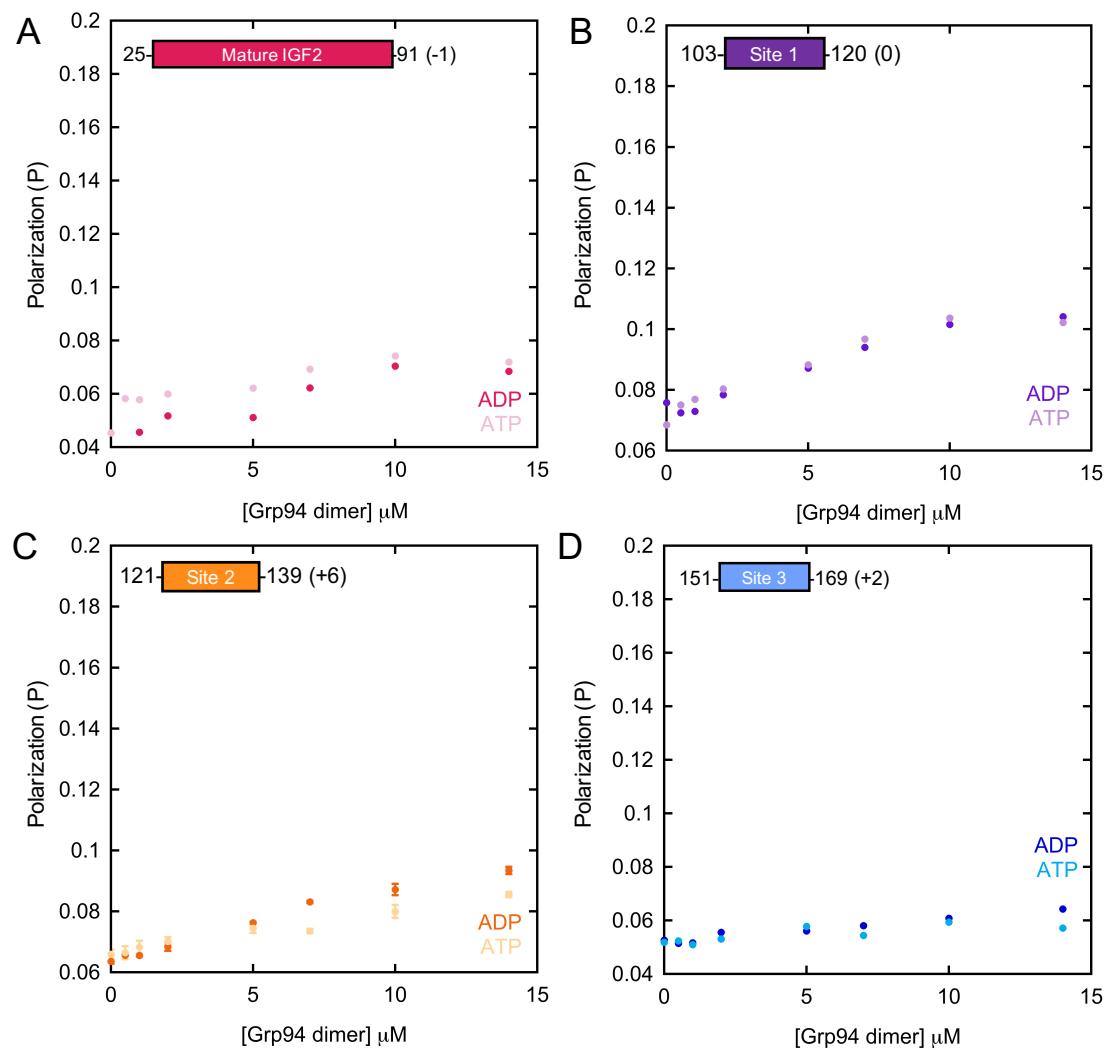

552 Supplemental Figure 6. FP assay with FITC-labeled BiP binding-site peptides and mature IGF2 (1

553 cysteine mutant) in the presence of Grp94 and ADP or ATP. Error bars indicate SEM for 3 replicates, 554 where present. Y-axis is identical to Supplemental Figure 4 with BiP for comparison. 


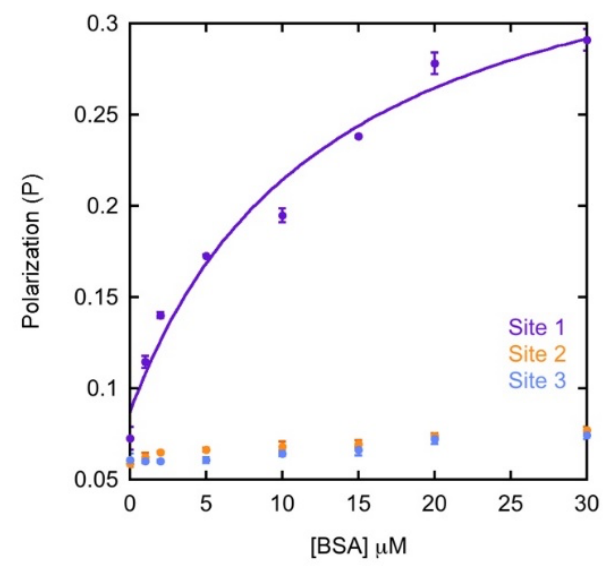

558 Supplemental Figure 7. FP assay with FITC-labeled site 1, 2, or 3 binding BSA. Solid line indicates fit to 559 equation $1\left(K_{D}: 13 \pm 2 \mu \mathrm{M}\right)$. Error bars indicate SEM of 3 trials.

560 

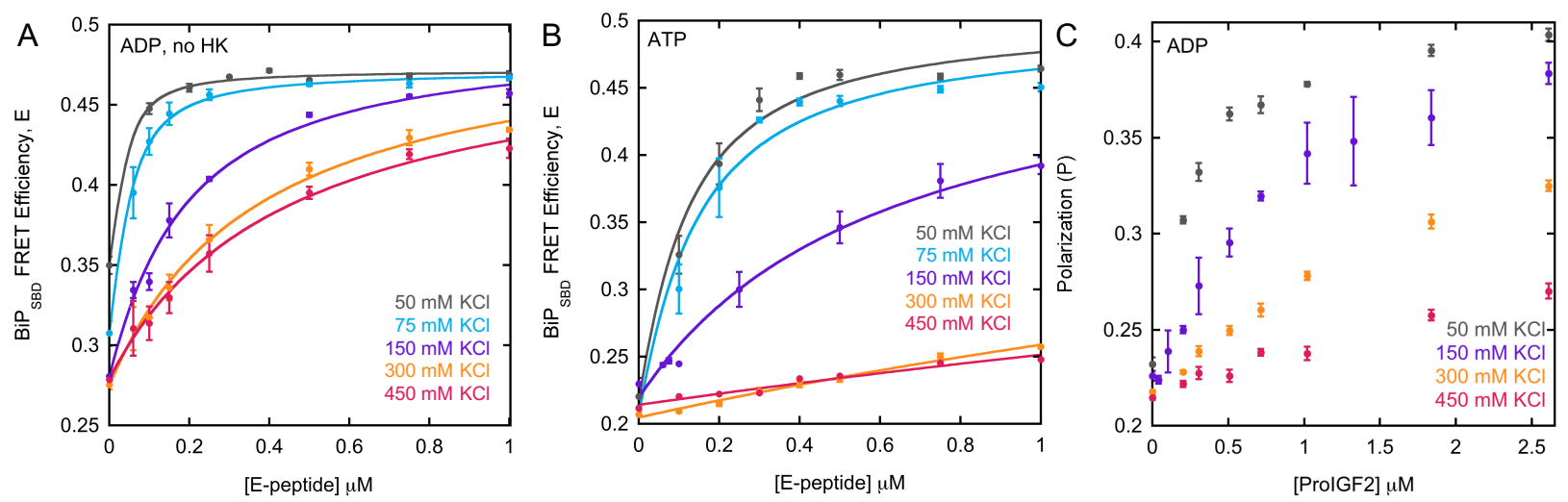

563 Supplemental Figure 8. BiP binding E-peptide and prolGF2 at increasing salt concentrations. (A) Salt-

564 dependence of $\mathrm{BiP}_{S B D}$ FRET assay with E-peptide oligomers and non-HK treated ADP. Fit values of binding affinity are shown in Figure 4A. Solid lines for 50,75 , and $150 \mathrm{mM} \mathrm{KCl}$ are a fit to equation 4, and lines for 300 and $450 \mathrm{mM} \mathrm{KCl}$ are a fit to equation 3. (B) Salt-dependence of the BiPSBD FRET assay with Epeptide oligomers under ATP conditions. Fit values of binding affinity are shown in Figure 4A. Solid lines

568 for 50 and $75 \mathrm{mM} \mathrm{KCl}$ are a fit with equation 4, and 150,300, and $450 \mathrm{mM} \mathrm{KCl}$ data are fit with equation 3 and a maximum FRET efficiency set to 0.5. (C) BiP binding prolGF2 oligomers as a function of increasing $\mathrm{KCl}$ concentration using FP assay with FITC-labeled BiP, in the presence of ADP. Error bars 571 indicate SEM for at least 3 replicates. 


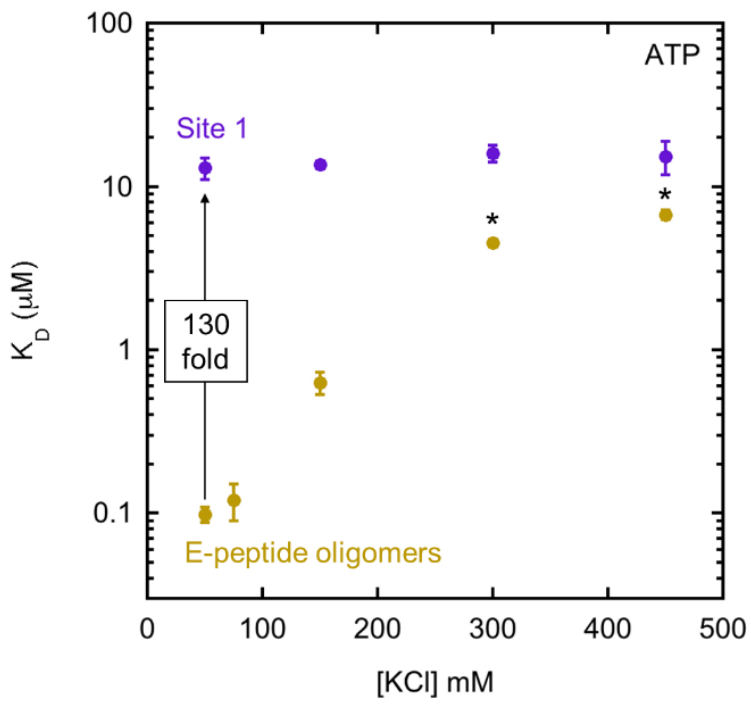

Supplemental Figure 9. Influence of salt on BiP's affinities for E-peptide oligomers and site 1 under

576 ATP conditions. $K_{D}$ data from E-peptide 103-120 is from FP data in Supplemental Figure 4A. $K_{D}$ data 577 from E-peptide from Supplemental Figure 8B. Error bars are the SEM for at least three replicates.

578 Asterisks indicate lower confidence of fitting, as described in Supplemental Figure 8B.

579

580 


\begin{tabular}{|c|c|c|c|c|c|c|}
\hline Client & Hsp70 & $\mathrm{K}_{\mathrm{D}}(\mu \mathrm{M})$ & Monomer? & $\begin{array}{l}\text { Net } \\
\text { charge }\end{array}$ & Nucleotide & Ref \\
\hline $\mathrm{C}_{\mathrm{H}} 1$ domain & $\mathrm{BiP}$ & $4.2 \pm 0.4$ & Yes & +1 & ADP & 31 \\
\hline HTFPAVL peptide & $\mathrm{BiP}$ & $11.6 \pm 0.6$ & Yes & 0 & ADP & 21 \\
\hline $\begin{array}{l}\text { MAPT MBD } \\
\text { Fibril }\end{array}$ & Hsp70 & $0.02 \pm 0.01$ & No & +10 & none & 7 \\
\hline MAPT MBD 10mer+ & Hsp70 & $0.17 \pm 0.04$ & No & +10 & none & 7 \\
\hline MAPT MBD 6-10mer & Hsp70 & $0.34 \pm 0.09$ & No & +10 & none & 7 \\
\hline MAPT MBD 3-5mer & Hsp70 & $0.97 \pm 0.19$ & No & +10 & none & 7 \\
\hline MAPT MBD 1-2mer & Hsp70 & $5.6 \pm 1.4$ & Yes & +10 & none & 7 \\
\hline MAPT 3R* & $\mathrm{Hsc70}$ & $0.31 \pm 0.05$ & $*$ & +10 & none & 36 \\
\hline MAPT 4R* & $\mathrm{Hsc70}$ & $0.16 \pm 0.04$ & $*$ & +13 & none & 36 \\
\hline$\alpha$-synuclein fibril & Hsp70 & $5.8 \pm 0.4$ & No & -9 & ATP & 8 \\
\hline$\alpha$-synuclein monomer & Hsp70 & $\sim 10$ & Yes & -9 & ATP & 8 \\
\hline NR peptide^ & $\mathrm{BiP}$ & 0.95 & Yes & +1 & none & 39 \\
\hline $\begin{array}{l}\text { leukocyte antigen } B * 2702- \\
\text { derived peptide } B w 4\end{array}$ & Hsp70 & 1.8 & Yes & +2 & ATP & 40 \\
\hline 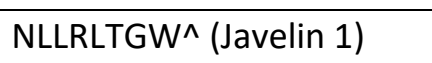 & Hsp70 & 0.9 & Yes & +1 & ADP & 34 \\
\hline Faf1 peptide^ (FYQLALT) & $\mathrm{Hsc70}$ & $4.3 \pm 0.9$ & Yes & 0 & ADP & 25 \\
\hline Faf1 peptide^ (FYQLALT) & $\mathrm{Hsc70}$ & $37-51$ & Yes & 0 & ATP & 25 \\
\hline Clathrin ${ }^{\#}$ & Hsp70 & 3 & No & -64 & $\begin{array}{l}90 \% \text { ADP, } \\
10 \% \text { ATP }\end{array}$ & 26 \\
\hline Clathrin" & Hsp70 & 12 & No & -64 & ATP & 26 \\
\hline
\end{tabular}




\begin{tabular}{|l|l|l|l|l|l|l|}
\hline $\begin{array}{l}\text { Cytochrome } c \text { peptide }{ }^{@} \\
\text { (IFAGIKKKAERADLIAYLKQAT } \\
\text { AK) }\end{array}$ & Hsp70 & 7 & Yes & +4 & $\begin{array}{l}\text { 90\% ADP, } \\
10 \% \text { ATP }\end{array}$ & 26 \\
\hline $\begin{array}{l}\text { Cytochrome } c \text { peptide } \\
\text { (IF }\end{array}$ & Hsp70 & 300 & Yes & +4 & ATP & 26 \\
\hline
\end{tabular}

583 Supplemental Table 1. Compilation of Hsp70 family dissociation constants towards client proteins.

584 *Oligomerization state for MAPT 3R and 4R not stated. " Clathrin sequence from $B$. taurus and net

585 charge calculated with one heavy chain and one light chain A. Net charge calculated with one heavy

586 chain and one light chain B is -58 . @ Peptide from $C$. livia sequence. ${ }^{\wedge}$ indicates synthetic client

587 sequences. All other client sequences are from $\mathrm{H}$. sapiens. Peptide clients are assumed to be 588 monomeric.

589

590

591 


\begin{tabular}{|c|c|c|c|c|c|}
\hline Client & $\mathrm{K}_{\mathrm{D}}(\mu \mathrm{M})$ & Monomer? & Net charge & Nucleotide & Ref \\
\hline Peptide $p^{*}$ & 0.06 & Yes & +4 & ADP & 41 \\
\hline Peptide $p^{*}$ & 2.2 & Yes & +4 & ATP & 41 \\
\hline $\begin{array}{l}\text { human telomere repeat binding factor } \\
1 \text { (hTRF1) } 377-430\end{array}$ & $1.4 \pm 0.2$ & Yes & +10 & ADP & 42 \\
\hline $\begin{array}{l}\text { human telomere repeat binding factor } \\
1 \text { (hTRF1) } 377-430\end{array}$ & $18 \pm 3$ & Yes & +10 & ATP & 42 \\
\hline Islet amyloid polypeptide (H. sapiens) & $\sim p M$ & No & +2 & apo & 35 \\
\hline$\sigma^{32}$ peptide (Q132-Q144) (E. coli) & 0.078 & Yes & +5 & apo & 43 \\
\hline$\sigma^{32}$ (E. coli) & 5 & Yes & -6 & apo & 44 \\
\hline
\end{tabular}

593 Supplemental Table 2. Compilation of representative DnaK dissociation constants towards client

594 proteins. *CALLQSRLLLSAPRRAAATARA, derivative of chicken mitochondrial aspartate aminotransferase 595 signal sequence.

596

597

598

599 


\section{References}

602 1. Rosenzweig, R., Nillegoda, N. B., Mayer, M. P. \& Bukau, B. The Hsp70 chaperone network. Nat. Rev. Mol. Cell Biol. 20, 665-680 (2019).

2. Mayer, M. P. \& Gierasch, L. M. Recent advances in the structural and mechanistic aspects of Hsp70 molecular chaperones. J. Biol. Chem. 294, 2085-2097 (2019).

606

3. Mayer, M. P. \& Bukau, B. Hsp70 chaperones: Cellular functions and molecular mechanism. Cell. Mol.

607 Life Sci. 62, 670-684 (2005).

608

609

610

4. Imamoglu, R., Balchin, D., Hayer-Hartl, M. \& Hartl, F. U. Bacterial Hsp70 resolves misfolded states and accelerates productive folding of a multi-domain protein. Nat. Commun. 11, 365 (2020).

5. Yang, J., Nune, M., Zong, Y., Zhou, L. \& Liu, Q. Close and Allosteric Opening of the PolypeptideBinding Site in a Human Hsp70 Chaperone BiP. Structure 23, 2191-2203 (2015).

6. Bertelsen, E. B., Chang, L., Gestwicki, J. E. \& Zuiderweg, E. R. P. Solution conformation of wild-type E. coli Hsp70 (DnaK) chaperone complexed with ADP and substrate. Proc. Natl. Acad. Sci. U. S. A. 106, 8471-8476 (2009).

7. Kundel, F. et al. Hsp70 Inhibits the Nucleation and Elongation of Tau and Sequesters Tau Aggregates with High Affinity. ACS Chem. Biol. 13, 636-646 (2018).

8. Wentink, A. S. et al. Molecular dissection of amyloid disaggregation by human HSP70. Nature 1-6 (2020) doi:10.1038/s41586-020-2904-6.

9. Sferruzzi-Perri, A. N., Sandovici, I., Constancia, M. \& Fowden, A. L. Placental phenotype and the insulin-like growth factors: resource allocation to fetal growth. J. Physiol. 595, 5057-5093 (2017).

10. Jin, Y. et al. The ER chaperones BiP and Grp94 regulate the formation of insulin-like growth factor 2 (IGF2) oligomers. J. Mol. Biol. 166963 (2021) doi:10.1016/j.jmb.2021.166963. 
11. Duguay, S. J. et al. Post-translational Processing of the Insulin-like Growth Factor-2 Precursor. J. Biol. Chem. 273, 18443-18451 (1998).

12. Qiu, Q., Basak, A., Mbikay, M., Tsang, B. K. \& Gruslin, A. Role of pro-IGF-II processing by proprotein convertase 4 in human placental development. Proc. Natl. Acad. Sci. U. S. A. 102, 11047-11052 (2005).

13. Basak, A. et al. Enzymic characterization in vitro of recombinant proprotein convertase PC4. Biochem. J. 343 Pt 1, 29-37 (1999).

14. Cornish, J. et al. Preptin, another peptide product of the pancreatic $\beta$-cell, is osteogenic in vitro and in vivo. Am. J. Physiol.-Endocrinol. Metab. 292, E117-E122 (2007).

15. Cheng, K.-C. et al. Characterization of preptin-induced insulin secretion in pancreatic $\beta$-cells. J. Endocrinol. 215, 43-49 (2012).

16. Yang, G. et al. Circulating preptin levels in normal, impaired glucose tolerance, and type 2 diabetic subjects. Ann. Med. 41, 52-56 (2009).

17. Valenzano, K. J., Heath-Monnig, E., Tollefsen, S. E., Lake, M. \& Lobel, P. Biophysical and Biological Properties of Naturally Occurring High Molecular Weight Insulin-like Growth Factor II Variants. J. Biol. Chem. 272, 4804-4813 (1997).

18. UCSF Chimera-A visualization system for exploratory research and analysis - Pettersen - 2004 Journal of Computational Chemistry - Wiley Online Library. https://onlinelibrary.wiley.com/doi/abs/10.1002/jcc.20084.

19. Klimstra, W. B., Heidner, H. W. \& Johnston, R. E. The Furin Protease Cleavage Recognition Sequence of Sindbis Virus PE2 Can Mediate Virion Attachment to Cell Surface Heparan Sulfate. J. Virol. 73, 6299-6306 (1999).

20. Xue, B., Dunbrack, R. L., Williams, R. W., Dunker, A. K. \& Uversky, V. N. PONDR-FIT: A Meta-Predictor of Intrinsically Disordered Amino Acids. Biochim. Biophys. Acta 1804, 996-1010 (2010). 
21. Marcinowski, M. et al. Substrate discrimination of the chaperone BiP by autonomous and cochaperone-regulated conformational transitions. Nat. Struct. Mol. Biol. 18, 150-158 (2011).

22. Rosam, M. et al. Bap (Sil1) regulates the molecular chaperone BiP by coupling release of nucleotide and substrate. Nat. Struct. Mol. Biol. 25, 90-100 (2018).

23. Banerjee, R., Jayaraj, G. G., Peter, J. J., Kumar, V. \& Mapa, K. Monitoring conformational heterogeneity of the lid of DnaK substrate-binding domain during its chaperone cycle. FEBS J. 283, 2853-2868 (2016).

24. Liu, S. \& Street, T. O. 5'-N-ethylcarboxamidoadenosine is not a paralog-specific Hsp90 inhibitor. Protein Sci. 25, 2209-2215 (2016).

25. Takeda, S. \& McKay, D. B. Kinetics of Peptide Binding to the Bovine 70 kDa Heat Shock Cognate Protein, a Molecular Chaperone. Biochemistry 35, 4636-4644 (1996).

26. Greene, L. E., Zinner, R., Naficy, S. \& Eisenberg, E. Effect of Nucleotide on the Binding of Peptides to 70-kDa Heat Shock Protein (*). J. Biol. Chem. 270, 2967-2973 (1995).

27. Schneider, M. et al. BiPPred: Combined sequence- and structure-based prediction of peptide binding to the Hsp70 chaperone BiP. Proteins Struct. Funct. Bioinforma. 84, 1390-1407 (2016).

28. Phillips, R. B., Kondev, Jane, Theriot, J., Garcia, H. G. \& Orme, N. Physical biology of the cell. (2013).

29. Kegel, W. K. \& Schoot, P. van der. Competing Hydrophobic and Screened-Coulomb Interactions in Hepatitis B Virus Capsid Assembly. Biophys. J. 86, 3905-3913 (2004).

30. Muchowski, P. J. \& Wacker, J. L. Modulation of neurodegeneration by molecular chaperones. Nat. Rev. Neurosci. 6, 11-22 (2005).

31. Feige, M. J. et al. An unfolded $\mathrm{CH} 1$ domain controls the assembly and secretion of IgG antibodies. Mol. Cell 34, 569-579 (2009).

32. Buchanan, C. M., Peng, Z., Cefre, A. \& Sarojini, V. Preptin Analogues: Chemical Synthesis, Secondary Structure and Biological Studies. Chem. Biol. Drug Des. 82, 429-437 (2013). 
671 33. Jiang, Y., Fu, H., Springer, T. A. \& Wong, W. P. Electrostatic steering enables flow-activated von

672 Willebrand Factor to bind platelet glycoprotein, revealed by single-molecule stretching and imaging.

$673 \quad$ J. Mol. Biol. 431, 1380-1396 (2019).

674 34. Flechtner, J. B. et al. High-Affinity Interactions between Peptides and Heat Shock Protein 70

675 Augment CD8+ T Lymphocyte Immune Responses. J. Immunol. 177, 1017-1027 (2006).

676 35. Chilukoti, N. et al. Hsp70 Inhibits Aggregation of IAPP by Binding to the Heterogeneous

677 Prenucleation Oligomers. Biophys. J. 120, 476-488 (2021).

678 36. Sarkar, M., Kuret, J. \& Lee, G. Two motifs within the tau microtubule-binding domain mediate its

679 association with the hsc70 molecular chaperone. J. Neurosci. Res. 86, 2763-2773 (2008).

680

37. Kopp, M. C., Larburu, N., Durairaj, V., Adams, C. J. \& Ali, M. M. UPR proteins IRE1 and PERK switch BiP from chaperone to ER stress sensor. Nat. Struct. Mol. Biol. 26, 1053-1062 (2019).

682

38. Stetefeld, J., McKenna, S. A. \& Patel, T. R. Dynamic light scattering: a practical guide and applications in biomedical sciences. Biophys. Rev. 8, 409-427 (2016).

39. Yang, J. et al. Conformation transitions of the polypeptide-binding pocket support an active 685 substrate release from Hsp70s. Nat. Commun. 8, 1201 (2017).

40. Maeda, H. et al. Biological Heterogeneity of the Peptide-binding Motif of the 70-kDa Heat Shock Protein by Surface Plasmon Resonance Analysis*. J. Biol. Chem. 282, 26956-26962 (2007).

41. Siegenthaler, R. K. \& Christen, P. Tuning of DnaK Chaperone Action by Nonnative Protein Sensor 689 DnaJ and Thermosensor GrpE*. J. Biol. Chem. 281, 34448-34456 (2006).

42. Sekhar, A., Rosenzweig, R., Bouvignies, G. \& Kay, L. E. Mapping the conformation of a client protein through the Hsp70 functional cycle. Proc. Natl. Acad. Sci. 112, 10395-10400 (2015).

43. McCarty, J. S. et al. Regulatory Region C of theE. coliHeat Shock Transcription Factor, $\sigma 32$, (1996). 
695 44. Gamer, J. et al. A cycle of binding and release of the DnaK, DnaJ and GrpE chaperones regulates

696 activity of the Escherichia coli heat shock transcription factor sigma32. EMBO J. 15, 607-617 (1996).

697 